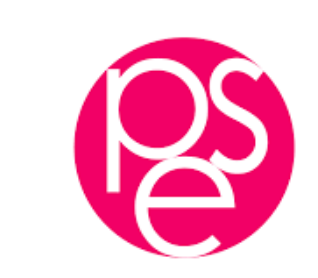

PARISSCHOOLOFECONOMICS
ECOLED'ECONOMIEDEPARIS

WORKING PAPER Nº $2018-58$

French Favored Redistributions Derived From Surveys:
a Political Assessment of Optimal Tax Theory

\author{
Adrien Fabre
}

JEL Codes: D31, D63, H21, P16

Keywords : Preferences for redistribution, Desired tax, Income tax rates, Income distribution, France

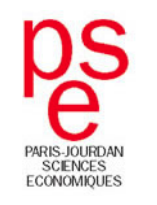
www.pse.ens.fr 


\title{
French Favored Redistributions Derived From Surveys: a Political Assessment of Optimal Tax Theory
}

\author{
Adrien Fabre
}

the date of receipt and acceptance should be inserted later

\begin{abstract}
An original method to find the shape of favored redistributions is presented, which is in turn used to assess the political acceptability of the optimal tax theory. Two surveys have been conducted in 2016 to quantify French preferences for income redistribution. In the first survey, respondents picked their preferred values for parameters which were used to determine the shapes of redistributions. These parameters included the proportion of winners and losers from a tax reform, and the minimum guaranteed income. Using different algorithms, several redistributions were derived from the interpolation of the median choices of each parameter ( $50 \%$ of winners, $10 \%$ of losers and a monthly demogrant of $800 €$ ). They resulted in transfers from high to low incomes of one tenth of the national disposable income. In the second survey, a majority of respondents agreed on implementing these redistributions. These results are in line with previous literature and robust to alternative specifications. Interestingly, the average desired redistribution corresponds closely to the shape of the optimal taxation derived from an utilitarian criterion. This allowed to show that this redistribution fails to obtain a significant majority support (contrarily to others), despite its good reception in a setting inhibiting self-interest. Finally, this study provides evidence that French citizens support a more direct democratic procedure to define the income tax rates, and describes a way to do so.
\end{abstract}

Keywords Preferences for redistribution, Desired tax, Income tax rates, Income distribution, France

JEL classification: D31, D63, H21, P16.

Acknowledgements I am grateful to Labex OSE Ouvrir la Science Economique for providing funding. I am deeply indebted towards Étienne Lehmann, Laurence Jacquet and Bruno Van der Linden for providing me their code. I am grateful to Stefanie Stantcheva, Michael I. Norton and the Harvard Business School for allowing me to use their Qualtrics account to code the questionnaires; and to Matthew Weinzierl for letting me reproduce some of his figures. I am also very thankful to all those who have given me precious advice, notably Malo Huard. This work was undertaken while I was a student at the École Normale Supérieure.

Adrien Fabre

Paris School of Economics, Université Paris 1, 48 bd Jourdan, 75014, Paris E-mail: adrien.fabre@psemail.eu Tel.:+33610379051, orcid: orcid.org/0000-0001-5245-7772 


\section{Introduction}

A growing literature uses surveys to exhibit determinants for preferences over income distribution, quantify the inequality aversion, measure its evolution and compare inclinations in different countries 11 A general finding emerging from international surveys such as the 2009 International Social Survey Program (ISSP) is that, in almost every country, a majority of people supports that it is "the government's responsibility to reduce income differences". Indeed, over the 40 surveyed countries, such a proposition fails to obtain a majority only in New Zealand (42\%) and in the United States (US, 33\%): overall, only $14 \%$ of the respondents disagree with the statement while $72 \%$ agree (among nonmissing answers).

Despite a growing interest for preferences over distribution, only a few studies focus on determining the desired extent of inequality or on defining and quantifying the preferred distribution (or redistribution) of a country, or at least study their parameters. Among them, Singhal (2008) and Forsé and Parodi (2015) quantify desired rates for the income tax, by direct questions on the preferred level of taxes at four levels of income (respectively for seven OECD countries using ISSP 1996, and for France using Dynegal - a 2014 survey). Both results seem in line with current income tax rates. Nonetheless, the view that respondents do not want a more progressive tax system seem contradicted by other results, including results from these same surveys: for example, in Dynegal, $60 \%$ agree for an increase of taxes on the wealthiest even if they may flee from France, $51 \%$ stand for a range between minimum and maximum incomes of 1 to 10 or below, and $72 \%$ find the French tax system unfair or very unfair. This discrepancy can be explained by at least two factors other than mere inconsistency. Firstly, when asked directly for the appropriate level of income tax rates, respondents may have restricted their answers to non-negative values because of their representation of what a tax is: this zero lower bound surely pushed up answers of rates for low and middle-income. Secondly, respondents may roughly agree with tax rates in the income range tested in the survey 2 while desiring a more redistributive policy outside these bounds. This suggests that a survey should be administered with more degrees of freedom to define income tax rates, allowing for more than four different levels of income and for negative tax rates. This is precisely what Weinzierl (2014) undertook in his own survey, by asking American people to rank different tax systems (graphically presented). Weinzierl also finds that preferred income tax rates in the US roughly correspond to the actual tax schedule. This is less surprising than for the 8 countries examined by Singhal, Forsé and Parodi, because Americans do not believe that it's the government responsibility to reduce income differences. Indeed, 51\% of American respondents disagree or strongly disagree with that idea, whereas $51 \%$ of French respondents strongly agree with it (among non-missing answers, in ISSP 2009).

While Weinzierl was interested in eliciting the criteria that Americans implicitly use to judge a tax system they broadly accept, another research question emerges in the French context since surveys like Perceptions des Inégalités et Sentiments de Justice (PISJ, 2009) has shown that 60\% are favorable (strongly or not) to "an increase of taxes in order to redistribute the surplus to the least fortunate" and that an overwhelming $89 \%$ of French people agree (strongly or not) that "differences between high and low incomes should be reduced" in their country. Knowing that the French favor a redistributive reform, arises the question: which reform do they want? What redistribution(s) would satisfy their desire for a reform while still obtaining a majority support?

Until now, the literature has largely ignored these questions, focusing instead on theoretical ones such as "What distribution of incomes would best conciliates fairness and efficiency?". The latter question is addressed by the theories of optimal taxation and redistributive justice, and resolved by assuming a normative criterion (see e.g. Piketty and Saez 2013; Fleurbaey and Maniquet 2017). Using the correspondence between ethical criteria and tax schedules, the so-called inverseoptimum literature reverse-engineers tax systems to reveal the implicit criteria that would make current income tax rates optimal (see e.g. (Bourguignon and Spadaro, 2012; Bargain et al., 2014; Hendren, 2014; Chang et al., 2017)). To reconcile this strand of the literature with extensive survey evidence which shows that current tax progressivity rarely reflects a majority's preference, one should concede that the revealed criterion of the social planner are misaligned with those of a majority 3 Yet another consideration questions the practical application of the optimal tax theory in a democracy: nothing guarantees that any optimal tax schedule could gather a majority approval.

\footnotetext{
1 See Fabre (2016) for a thorough review of this literature.

2 The income range stretched from $1100 €$ to $12000 €$ per month in Dynegal, and exhibited comparable values in ISSP 1996.

3 One can wonder how the majority's preference could be overlooked in a democracy. The explanation which fits best survey evidence (from France) is that citizens do not determine their vote primarily over tax reforms proposals, and give more weight to other points of the programs, such that the European Union, the deficit or immigration
} 
In order to investigate the political acceptability of redistributive reforms - identified as a majority approval, the problematic needs to depart from the pursuit of the optimal tax and becomes: "What redistributions would (a majority of) people support?".

Using a methodology specially conceived to address this problem of political economy, two surveys were conducted in 2016 whose results are consistent with the French endorsement of an additional redistribution. Not only the first survey was helpful to investigate in detail preferences for the tax system, but it allowed to define the shape of three redistributions directly from the median answers to key parameters of a reform: the demogrant, and the proportions of people that should be advantaged and disadvantaged by a reform. The relevance of this original procedure was demonstrated throughout the second survey, as respondents have clearly expressed their support for the redistributive reforms derived from the answers of the first survey. Then, the results allowed to assess empirically the political reception of the main criteria used in the optimal taxation literature: the Rawlsian and utilitarian ones. These criteria appear to be well evaluated, but they lack of political acceptability, given the (relatively) high proportion of disadvantaged people they imply. Indeed, the most widely approved reform entails a redistribution of similar extent to those derived from the theory, but concentrates the burden to fewer people at the top. Thanks to a novel methodology, this accepted redistribution is certainly the most precise and favored one to have been elicited from surveys until now. Its shape confirms unambiguously the usual result that a majority of people supports further redistribution of incomes. That being said, this paper remains a tentative work, in the French context, that gives only a partial answers to the uncovering of preferred reforms, as the redistributions proposed are too simple to be on par with the necessary complexity of a tax reform.

Still, this paper brings three main contributions: introducing a method which successfully elicited favored redistributions, presenting these redistributions with their key parameters, and estimating the acceptability of reforms derived from the optimal tax theory. The surveys will be presented in section 1 . Their raw results will be exposed in section 2, as well the determinants of redistributive preferences and the reception of the utilitarian and Rawlsian criteria. A discussion will ensue in section 3, which will notably show the robustness of this method, and envisage a more direct inclusion of the citizens' preferences in the shaping of tax schedules.

\section{Presentation of the Surveys}

\subsection{Data Collection (and Data Cleansing)}

The surveys were conducted in September and October 2016 on two separate representative samples of one thousand of French adults each 4 The respondents were picked by the company Bilendi from the 700,000 persons of the Access Panel On-line Bilendi (which is continuously filtered to improve its quality), and remunerated through gift points tantamount to 3 euros.

The method of quotas insured a priori representativeness according to five socio-demographic characteristics: age (7 brackets), sex, socio-professional category (8), size of town (5) and region (9, solely in metropolitan France), while an a posteriori weighting accounted for the overrepresentation of highly educated people 5 To insure the robustness of results to alternative specifications, a third survey was administered in July 2018 on a separate sample of 1000 French adults, where representativeness was insured using the five set of quotas above together with quotas on the education level (see Appendix 3.1). As the surveys included several graphs and interactive animations, they have been administered on-line, on each respondent's computer. Although results from computer-based surveys may differ significantly from face-to-face or telephone interviews, as pointed out by Parodi (2014), it is unclear which method of administration is less biased (as compared to voters' preferences). The attrition rate (measuring the proportion of respondents who started but did not complete the survey) was respectively $10 \%$ and $30 \%$ in the first and second survey 6 The response time was a priori estimated to 20 minutes, and opportunist respondents who answered in less than 9 minutes were screened out. A posteriori, the median response time for accepted respondents in each survey was respectively 18.4 and $20.6 \mathrm{~min}$. In order to spot

policies. Another explanation would be that the government does not represent a majority of people, which can be true with the French electoral system.

4 To be precise, respectively 1007 and 997 persons.

5 See Appendix 2.1 for a robustness check with unweighted data, and on-line documentation for more details on the sampling method (in French). All sources are available here: adrien-fabre.com/documents.php\#sondages (see Données complètes for ready-to-use dataset); a codebook and the questionnaires are also provided.

6 The higher figure in the second survey is due to a bug in the beginning of its implementation, which did not affect the results (because only complete answers were retained). 
inattentive respondents, a test of quality of the responses was inserted. It consisted in adding a choice labeled "Please tick 'Slightly decrease' (test of quality of your answer)" inside a matrix with multiples questions and multiple choices (themselves ranging from "Strongly increase" to "Strongly decrease"). Between $16 \%$ and $24 \%$ failed this test, depending on the survey. Still, it would be excessive to consider all these respondents as phony or lacking of seriousness. Indeed, as I submitted personally the questionnaires to a dozen of people before launching the surveys, I noticed that some people did not understand this test and responded "I don't know" or "Indifferent" (the choice that looked the most neutral), like the majority of those who failed this test. Finally, the final (or restricted) sample was constituted from the original (or augmented) sample after the elimination of the respondents who did not complete the questionnaire, who responded too quickly, who failed the test of quality or whose quota was already full. The broader augmented sample is used as an alternative one to test the robustness of the results in Appendix 2.1.

\subsection{Survey Questions and Methodology}

The surveys contained many questions on fiscal and political preferences that are outside the scope of this article. However, their main questions were dedicated to the study presented here, and were designed to infer a precise redistribution supported by a majority of French people. In this subsection, I will detail in turn the source and variable used to plot the current distribution, the procedures chosen to derive a redistribution from a few key parameters, and the redistributions derived from the typical answers to the first survey, hereafter referred to as the proposed redistributions.

\subsubsection{Sources and Variables}

All the data used to plot the distributions is taken from the Enquête sur les Revenus SocioFiscaux (ERFS 2012) produced by INSEE (the French national statistics bureau). The standard variable of the ERFS which allows to present income inequalities at the household level - arguably the most relevant level to consider them - is the equivalised disposable income (or niveau de vie), which equals the disposable income of the household divided by its number of consumption units 7 This variable has been used in a question where respondents had to grade different income distributions between -2 and +2 (see section 2.3). However, a variable at the individual level was preferred for the main questions. In effect, a redistribution derived from their previous answers was proposed to each respondent in the first survey, as well as an interactive graph where s-he could fine-tune their preferred redistribution. The algorithms which computed interactively the displayed redistribution from a change in the parameters featured a simple constraint on the aggregate income: the latter was assumed to stay constant throughout the redistribution 8 Indeed, the constraint on the aggregate income ought to be simple to optimize the loading time and the treatment of the data. Additionally, at variance with household variables, individual incomes simply sum up to the aggregate (national) income. Because of this computational ease, and as an individual variable can still be satisfactory to study income inequalities, the individual disposable income was adopted. It was defined for the occasion, by imputing the disposable income to the adult members of the household. Non-contributive social benefits were imputed to the least contributor(s) of the household, while other incomes were imputed to their respective entitled person 9

\subsubsection{Parameters Determining the Redistribution}

Defining a redistribution consists in deriving a future distribution from a current distribution, using an algorithm fed with some parameters. In order to limit the number of such parameters, four strategic points have been chosen on the cumulative density function of incomes, through which the future distribution will pass (when possible). These points correspond to the bounds of the income distribution: the demogrant and the maximum income, and to the crossing points with the current distribution: the quantile of adults advantaged and disadvantaged by the reform (between which

\footnotetext{
7 Following Eurostat the INSEE defines the number of consumption units by summing different weights for each household member: 1 for the household head, 0.5 for each additional person aged 14 or more, and 0.3 for each child below the age of 14 .

8 Behavioral responses were taken into account by another mean.

9 When some income was not attributable to a peculiar individual by this method (which was the case for capital income), it was allocated pro rata according to the contribution of each adult in the household (excluding non-contributive benefits).
} 
the current and future distribution coincide). The persons advantaged (respectively disadvantaged) by the redistribution are assumed to have the lowest (resp. the highest) incomes, which restricts our set of allowed redistributions to redistributive ones (in accordance with previous insights on French preferences). Furthermore, it is worth noting that the maximum income plays here little role, in the sense that in practice, its value does not affect the shape of the redistribution, so that the results are similar to a situation with no maximum income (which is equivalent in the algorithm to assigning an arbitrarily high value to this parameter).

If the number of parameters has been limited to keep the questions easy to understand, this choice is not meant to convey the idea that the aforementioned parameters constitute the best reduced form to express a redistribution. Indeed, I do not defend that a redistribution can be satisfactorily outlined using only four parameters. The goal of this method is simply to elicit a supported redistribution, and any other method achieving that purpose would be appreciated, be it using other and/or more parameters.

Let us now detail the questions asked in the survey about these parameters. For all these questions, the respondents had to type their answers in an entry field (see Appendix B for screen shots). Also, a different variant of each question (among two to four) was randomly allocated to each respondent. Finally, the values of the parameters were computed from the weighted augmented sample of the first survey, in order to gain in the precision of the estimates. The values obtained then and reported in this subsection are much the same as those from the restricted sample of the first survey as well as those from the restricted samples of all surveys combined, which constitute the final results that are presented in subsequent figures. The summary statistics of the variables for the different samples are presented in Appendix A. As for the few questions further mentioned that did not enter in the computation of the parameters, all statistics are given from the final results.

Fig. 1: Key parameters of a redistribution: the demogrant and the bounds where current and future distribution coincide

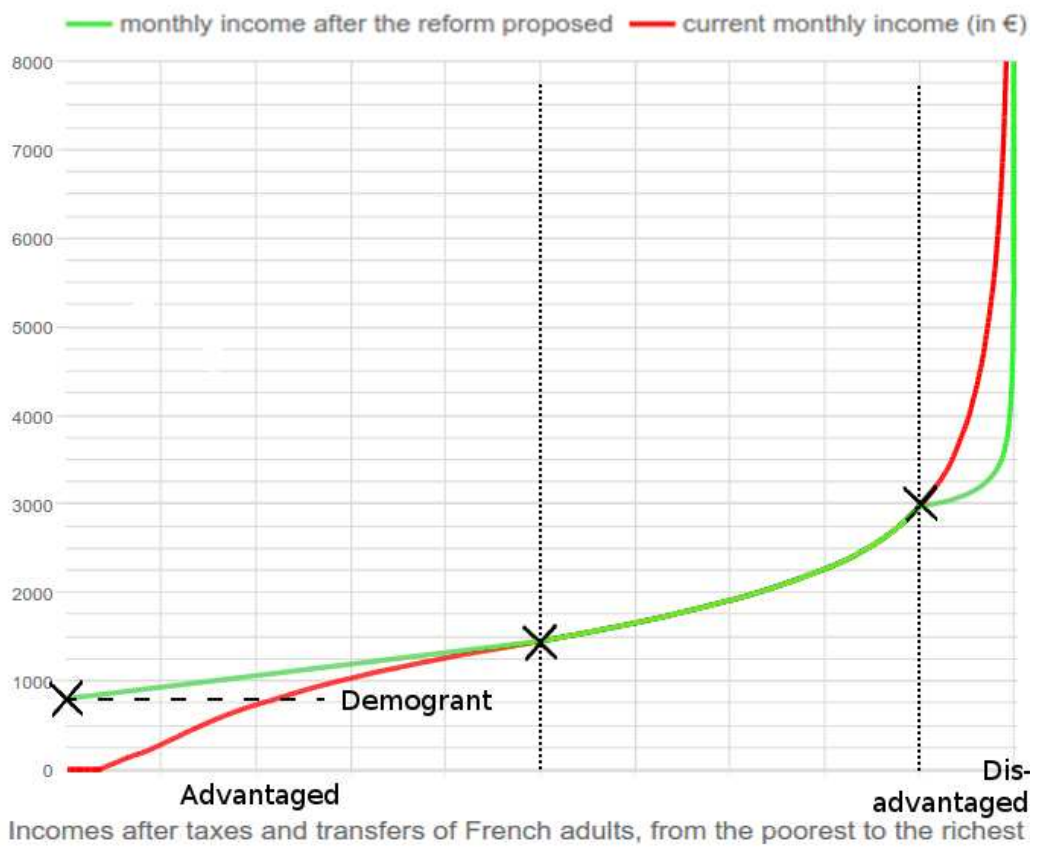

The demogrant Four variants of the question have been asked, which allow to assess the importance of the phrasing in such questions and help understand the expectations of the population over the welfare state. The wording that seems to better correspond to the demogrant is "What should be the amount of welfare [aides de l'État] for those who have no income?": over the $64 \%$ of non-missing answers, the median is $800 € /$ month (see Appendix C for the density of answers and Appendix $\mathrm{B}$ for the phrasing of questions) 10 Other phrasings (the amount of a basic income, the minimum amount guaranteed to all, or how much the state should insure to all) have resulted in much higher

10 The median for the final sample (combined both surveys) is slightly lower: 738€/month. However, the third survey introduced a similar but more precise phrasing which yielded a median of $800 € /$ month: "How much should receive a single person above 25 years-old who has no other income than social aid?" 
median answers (1000, 1200 and $1400 € /$ month, respectively), probably because the respondents interpreted them as pertaining to an ideal situation unreachable immediately, or thought of other mechanisms than social benefits, such as full-employment, to improve the most modest incomes. Indeed, only the answers to the former phrasing are compatible with other results, as can be shown with two pieces of evidence. Firstly, the desired trade-off in the reduction of inequalities clearly leans towards an increase in the minimum wage rather than in an increase in welfare benefits ( $65 \%$ vs. $7 \%$ of answers) 11 Secondly, a majority wishes to keep the Revenu de Solidarité Active (RSA socle) to its current level (37\% of answers) or below $(31 \%) 12$ RSA is a welfare benefit of $535 € /$ month for French people with no (or very low) income, which easily results in a demogrant of $785 € /$ month, once combined with housing benefit (which depends on the rent, the geographical area and the household structure, and averaged at $239 € /$ month in 2013) and Prime de Noël (a Christmas grant of $152 €$ ). After accounting for imperceivable in kind benefits (such as the gratuity of public transportation in the Paris area for RSA recipients), the French demogrant can be rounded up to $800 € /$ month, which is in line with the dominant preference to keep the demogrant at its current level.

Fig. 2: Demogrant: desired amounts depending on the phrasing of the question (in $€ /$ month)

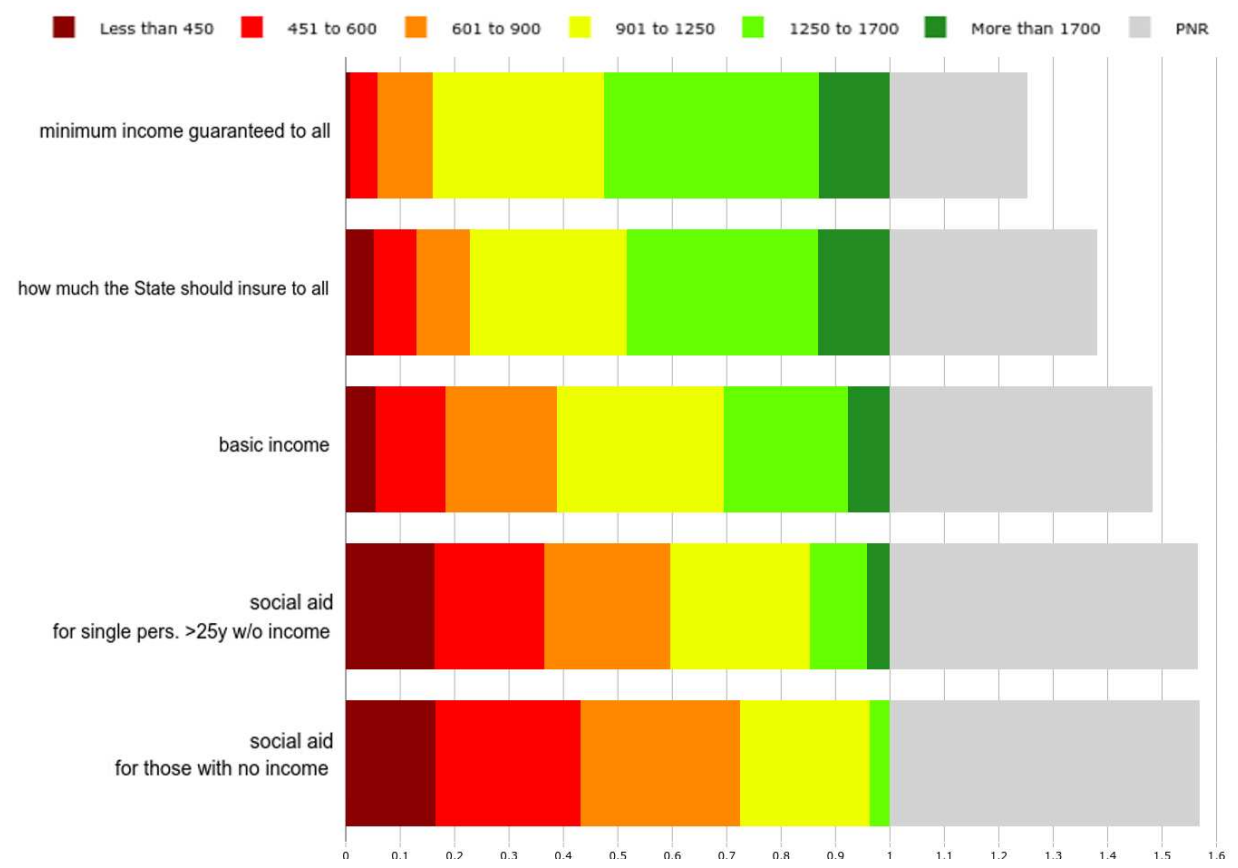

The maximum income Three variants were tested to determine the desired maximum income for France (if any): straightforwardly, the desired amount for the legal maximum income (hereafter legal max); in addition, the same question primed with an argument on the counter-productivity of taxing too much the richest people (legal max + anti-tax argument); and finally, the maximum income in an ideal society (ideal $\max ) 13$ Median answers of these variants were always finite: re-

\footnotetext{
11 This question was asked in the second survey, the remaining answers fan out as follows: $13 \%$ do not wish to reduce inequalities, and $16 \%$ choose "I don't know, I don't want to answer".

12 This result contrasts with the data from Piketty (2003) (the only previous study which directly asked for the desired amount for the RSA), which showed that the median person desired an increase of the RSA by $20 \%$ in 1999 (since, it has been increased by $9 \%$ in real terms). However, a median desired amount of (minimal) social aid of $750 € /$ month observed in the final sample is consistent with the findings of a 2015 survey from the DREES, which shows that $55 \%$ are favorable to an increase of the RSA, knowing that it is between $500 €$ and $760 € /$ month (taking housing benefits into account) - while $75 \%$ were in favor of an increase in 2009. Three reasons explain the lower support for an increase of the RSA in the recent surveys: its revaluation since 2012, a shift in views since the recession, and the framing of the question (people tend to be more supportive when the survey indicates the amount of the RSA, because they would not estimate it well otherwise, and/or because the survey omits housing benefits - which is the case in Piketty (2003)).

13 The phrasing of the variants were respectively: "In your opinion, what is the maximal income that should be legally established in France?"; the same question followed by "It is worth noting that above a certain threshold, the taxation of the richest if often counter-productive, because they move to another country or reduce their activity to avoid the tax increase"; and "If France was an ideal society, what would be the highest income? Let us precise that this question does not ask whether a legal ceiling ought to be established on French income: it simply amounts to
} 
spectively $100,000 € /$ month for legal max (44\% stated that they did not wish any ceiling on incomes, and their answer were counted as infinity while computing the median answer), 20,000€/month for legal max + anti-tax argument (36\% for infinity), and 15,000€/month for ideal max ( $16 \%$ for infinity). Interestingly, the priming had the opposite effect than expected: in effect, the anti-tax argument induced highly significantly lower answers for the (logarithm of) desired maximum income 14 This result may be a manifestation of the boomerang effect: indeed, Hovland et al. (1953) showed that when someone is pressured to make a certain choice, psychological reactance (theorized by Brehm (1966)) can cause her or him to resist this pressure by adopting an opposite alternative. It could also be explained by the priming which implies that rich people may not have a civic behavior, or suggests that they could escape from the worst consequences of a redistribution (by moving to another country), both reasons making a case for a more stringent maximal income.

The simple phrasing (legal max) was logically chosen to set the value of the parameter, to its median answer of $100,000 € /$ month. It is worth noting that the final median answer to the simple phrasing (when taking due account of both surveys) proved somewhat higher: it is $250,000 €$ /month. But in any case, as already mentioned, such difference in the value of this parameter has no impact on the shape of the graph presented to the respondent. Finally, these results are mostly relevant for themselves: it is interesting to learn that French are rather in favor of a ceiling on incomes.

Fig. 3: Maximum income: desired amounts depending on the phrasing of the question (in $€ /$ month)

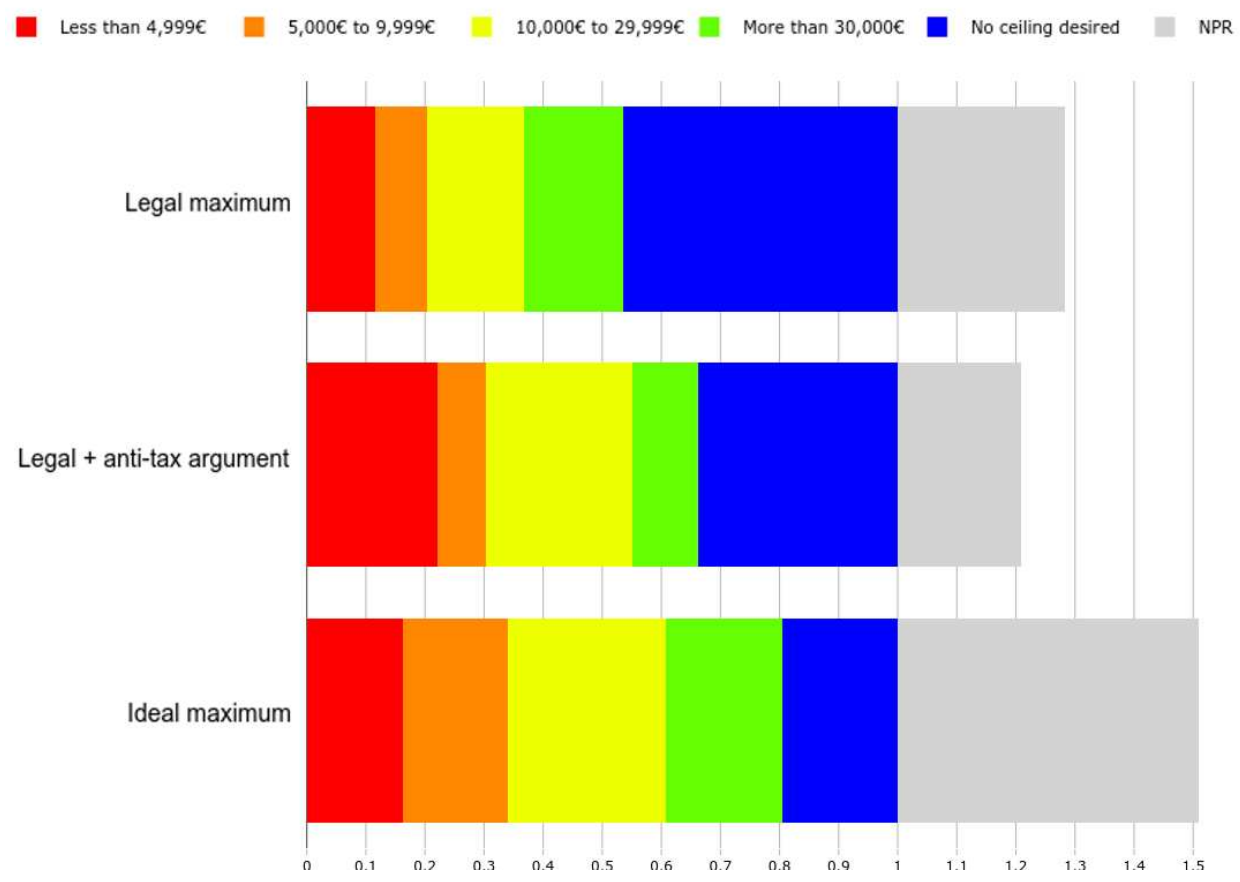

The proportion of dis/advantaged by the reform The last two parameters were given by two similar questions, which asked for the preferred proportion of persons to advantage, or to disadvantage, through a redistribution of incomes from the richest to the poorest 15 A slider was provided graphically to help the respondents, which indicated the income corresponding to each percentile of the distribution. The answers are slightly different in the second survey, where the distribution was given in terms of equivalised household disposable income instead of individual disposable income, indicating that respondents take into account both the proportion and the absolute level of income in their choice 16 That being said, the medians are in both cases $50 \%$ and $10 \%$ for the propor-

inquire what would be the highest income in a society with the appropriate level of inequalities." The respondents then had the possibility to choose the absence of limit, or not to answer, along the entry field.

14 See Appendix $\mathrm{F}$ for the results of all regressions.

15 Fabre (2016) relied on parameters expressed in absolute terms (e.g. the desired income for an unskilled worker) rather than in relative terms (such as the proportion to advantage) to infer desired redistribution. The former method does not allow to internalize the constraint on aggregate income on the answers, thereby burying the tradeoff between advantaging the poor and disadvantaging the rich. Hence, parameters expressed in relative terms have been chosen.

16 This is consistent with a similar finding in Saez and Stantcheva (2016). See Appendix F for the results and Appendix B to see the slider. 
tion of persons to advantage and disadvantage, respectively. They correspond to individual (resp. equivalised household) monthly incomes of $1450 €$ (resp. 1700€) and $2950 €$ (resp. 3150€).

Fig. 4: Dis/advantage: preferred percentage of French people to dis/advantage through a redistributive reform of the income tax

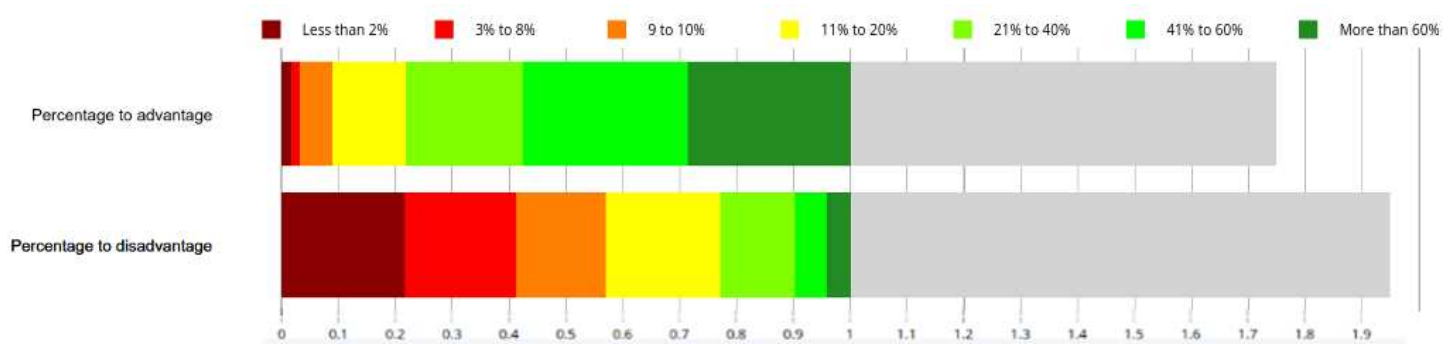

\subsubsection{Redistributions Derived From Survey Answers}

Two algorithms were used to derive different redistributions, they are explained in Appendix E and one can interactively play with them her ${ }^{17}$ and there ${ }^{18}$ These algorithms, as compared to others that have been imagined (relying e.g. on the Lorenz curve or on a non-parametric graphical definition), were preferred because of the simplicity of the questions which they rely upon. In addition to the parameters aforementioned, they require an additional parameter, named Extent, adjusted using known median preferences, which corresponds to the magnitude (coded between 0 and 10) of the transfer from rich to poor, other things equal. The four redistributive reforms summed up in Table 1 are described in details in the paragraphs and Figures below.

Table 1: Main characteristics of the proposed reforms

\begin{tabular}{ccccc}
\hline \hline proposed reform & demogrant median & average & median & distortionary median \\
\hline algorithm & demogrant & demogrant & Dis/adv & Dis/adv \\
distortion & No & No & No & Yes \\
method & median params & average customized & median params & close to median params \\
\hline demogrant (ש/m.) & 800 & 859 & 800 & 550 \\
advantage (\%) & 77 & 58 & 50 & 50 \\
disadvantage (\%) & 23 & 42 & 10 & 12 \\
\hline Gini (current: 0.43) & 0.29 & 0.25 & 0.24 & 0.25 \\
Transfer/GDP & 0.09 & 0.12 & 0.12 & 0.12 \\
\hline \hline
\end{tabular}

Algorithm Demogrant The first algorithm uses a unique neutral point instead of a range of quantiles between which the current and future distributions coincide. To determine this particular quantile which splits the population between advantaged and disadvantaged people (making everyone somewhat affected by the reform), I took the median answer to both variants combined (advantage and disadvantage). The neutral point obtained was $77 \%$, corresponding to an individual income of $2150 € /$ month. Besides, the parameter Extent was chosen so as to suit the median desire for an increase of the minimum wage observed in previous surveys. I considered that the minimum wage should correspond to the "minimum income below which one cannot make a decent living"19, whose median desired value was quantified in another survey (PISJ) to be $1360 € /$ month 20 Hence, the minimum wage (net of taxes and subsidies), amounting to $1280 € /$ month before the reform, was brought to $1360 € /$ month by setting Extent to 3.5. Finally, applying the algorithm with these parameters produced the demogrant median redistribution, presented in Figure 5.

17 Dis/adv: http://preferences-pol.fr/Politique\%20des\%20francais.html\#q19183287

18 Demogrant: http://adrien-fabre.com/sondage/Fiscalite\%20des\%20francais.html\#q21976492

19 The original phrasing (in French) was : "le revenu minimum mensuel net en dessous duquel on ne peut s'en sortir sans difficultés importantes".

20 This hypothesis was not accurate, see paragraph 3.1 .4 
The first survey included a question where the respondents could adjust the parameters of the first algorithm using sliders, in order to propose their own preferred reform. At the beginning of this interactive process, the two first sliders were set to their previous answers, while the slider for Extent was set at its middle value of 5 . The median answers at this question (to which $70 \%$ of the sample responded) were $1000 € /$ month for the demogrant, $56 \%$ for the proportion of advantaged, and 5 for Extent 21 A second redistribution, the average proposed reform, was computed by averaging all the reforms proposed by the respondents: it is shown in Figure 6 .

Fig. 5: The demogrant median proposed reform (Yes/No/PNR: 42/38/20\%)

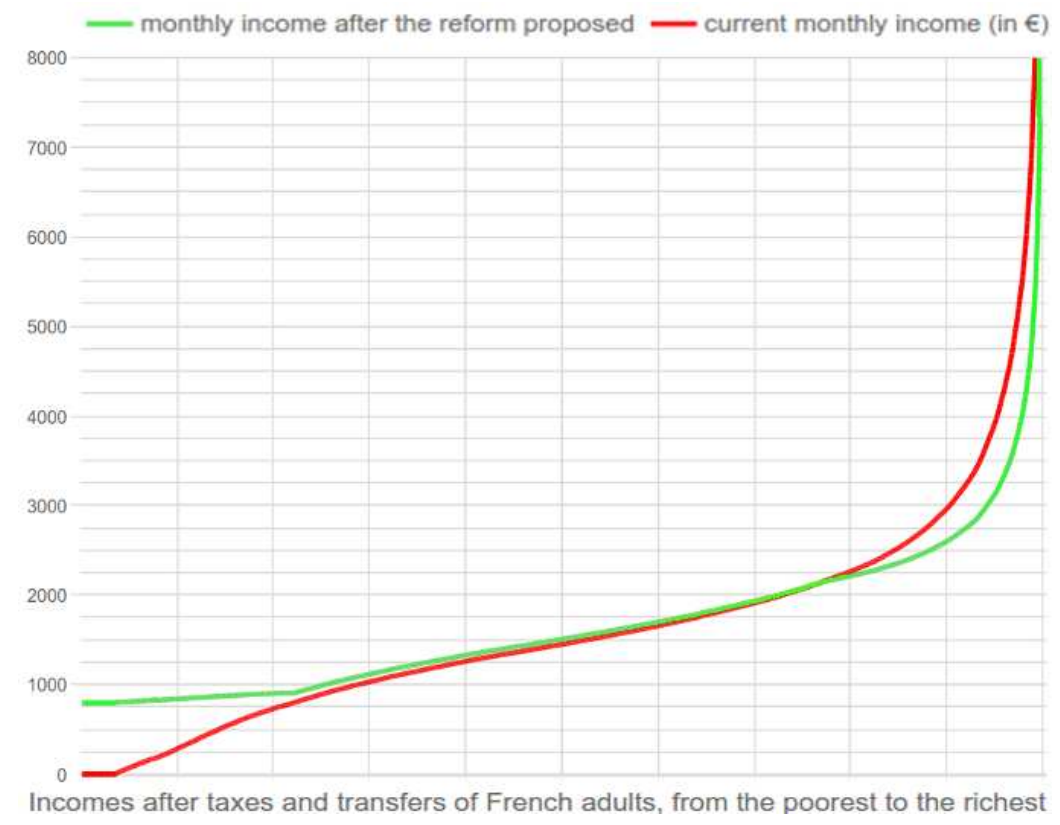

Fig. 6: The average proposed reform (Yes/No/PNR: 39/37/24\%)

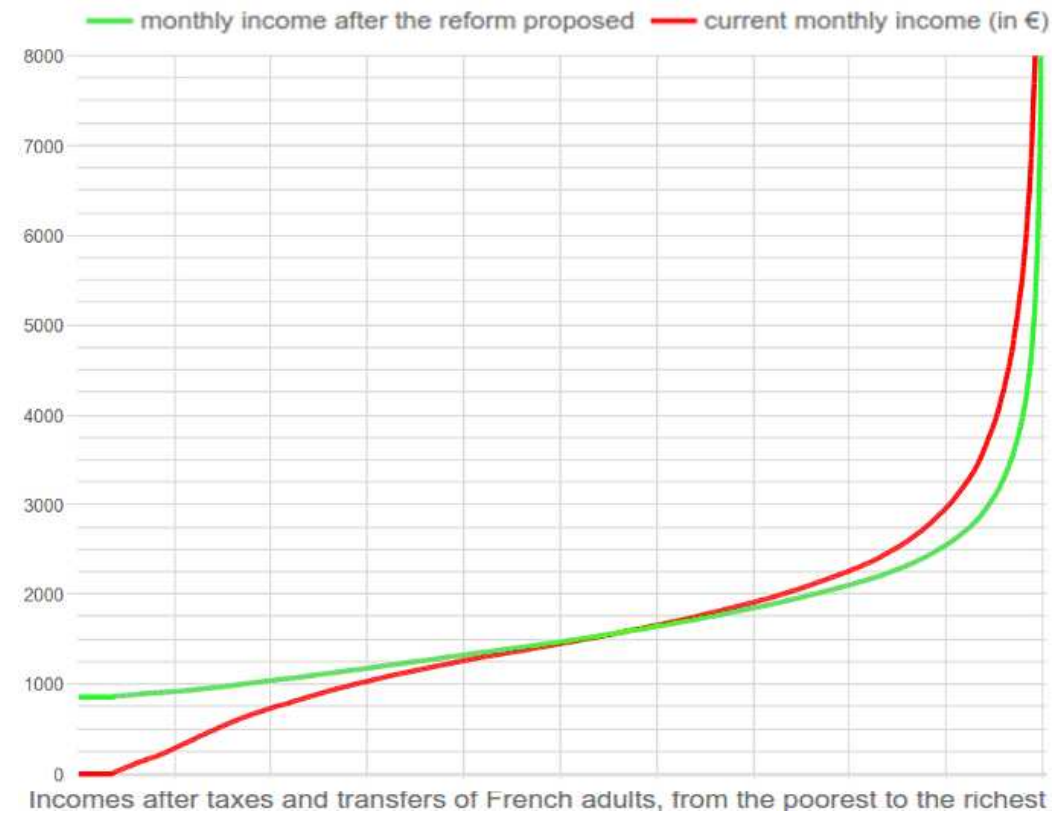

21 Only 5 respondents over 1007 filled the entry fields with the initial value of the parameters, suggesting that those who responded to this question did it sincerely and carefully.

Another version of the question used the other algorithm, Dis/adv, and its results are not presented because they are similar to those of the previous subsection: the median answers to advantage and disadvantage are the same, and the median for Extent is only slightly lower, between 7 and 8 . 
Algorithm Dis/adv The second algorithm uses both the preferred proportion of advantaged and disadvantaged people as parameters. The value of Extent (8.57) was chosen in such a way that the demogrant would equal its median preferred value. Therefore, the main difference between the demogrant median proposed reform (described above) and the median proposed reform (this is how this one is named) lies in lower middle of the distribution, where the former is less generous, and at the top, where the latter concentrates more the burden of the new transfer. The shape of the median proposed reform is shown in Figure 7.

Fig. 7: The median proposed reform (Yes/No/PNR: 52/26/22\%)

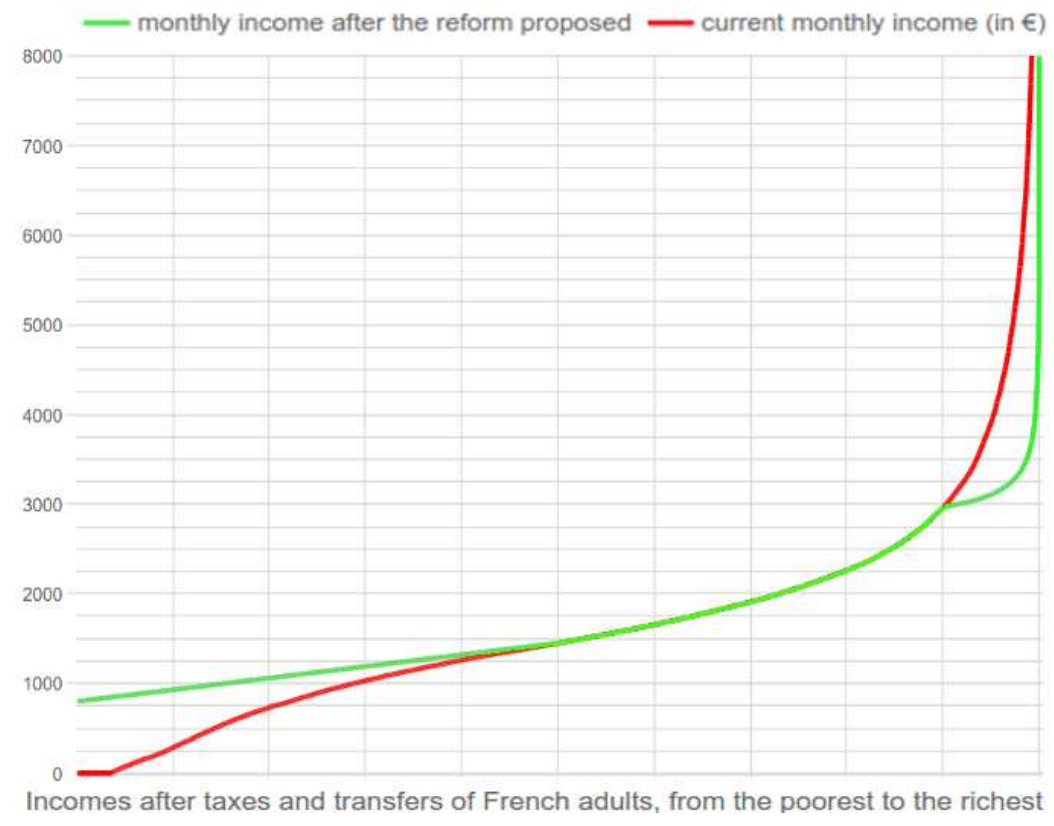

Admittedly, the three first proposed reforms did not address behavioral responses. Indeed, including a modeling of behavioral responses in the algorithm would have been too computationally intensive for an interactive program. In order to overcome this shortcoming, a supplementary parameter was added to the algorithms, which controls the variation in aggregate (disposable) income through the reform. Therefore, this parameter can be interpreted in two ways: as a proxy for behavioral responses or as a change in the government's budget. By setting this parameter to $5 \%$ of national (disposable) income, a last reform was proposed, named distortionary median proposed reform (see Figure 8). The value of 5\% roughly corresponds to the aggregate loss of consumption in redistributions of similar magnitude (see section 2.4 22 Removing $5 \%$ of national income while disadvantaging only the richest $10 \%$ led to cap all incomes at $3000 € /$ month, which was obviously not in accordance with the desired maximum income. Hence, the proportion of disadvantaged people was raised to $12 \%$ for this redistribution. Also, the budget was too tight to procure a decent demogrant, so one could not impede it to decrease, even after increasing the Extent to 923

\subsubsection{Approval and Evaluation of the Proposed Distributions}

The question inquiring about the approval of proposed distributions was phrased as follows:

Imagine a tax reform with the following characteristics: the actual income distribution of French people (in red) would be replaced by a more egalitarian distribution (in green); this reform would establish a basic income guaranteed to all of [demogrant] $€$ /month, would disadvantage the richest [disadvantage] $\%$ as compared to current situation but would advantage the poorest [advantage]\%; it would entail a transfer of [computed] $\%$ of GDP from the richest to the poorest, as compared to current situation.

\footnotetext{
$225 \%$ is also the median answer to another question of this survey: "What proportion of the income of rich countries should be transferred to poor countries?". However, interpreting this value as the desired increase in development aid would wipe out the intended capture of behavioral responses; thus, an interpretation in terms of a proxy for distortions should be preferred.

23 Setting Extent to its maximal value of 10 would have resulted in either an overwhelmingly low maximum income or an even higher proportion of disadvantaged people, so 9 was chosen as an acceptable trade-off.
} 
Fig. 8: The distortionary median proposed reform (Yes/No/PNR: 46/28/27\%)

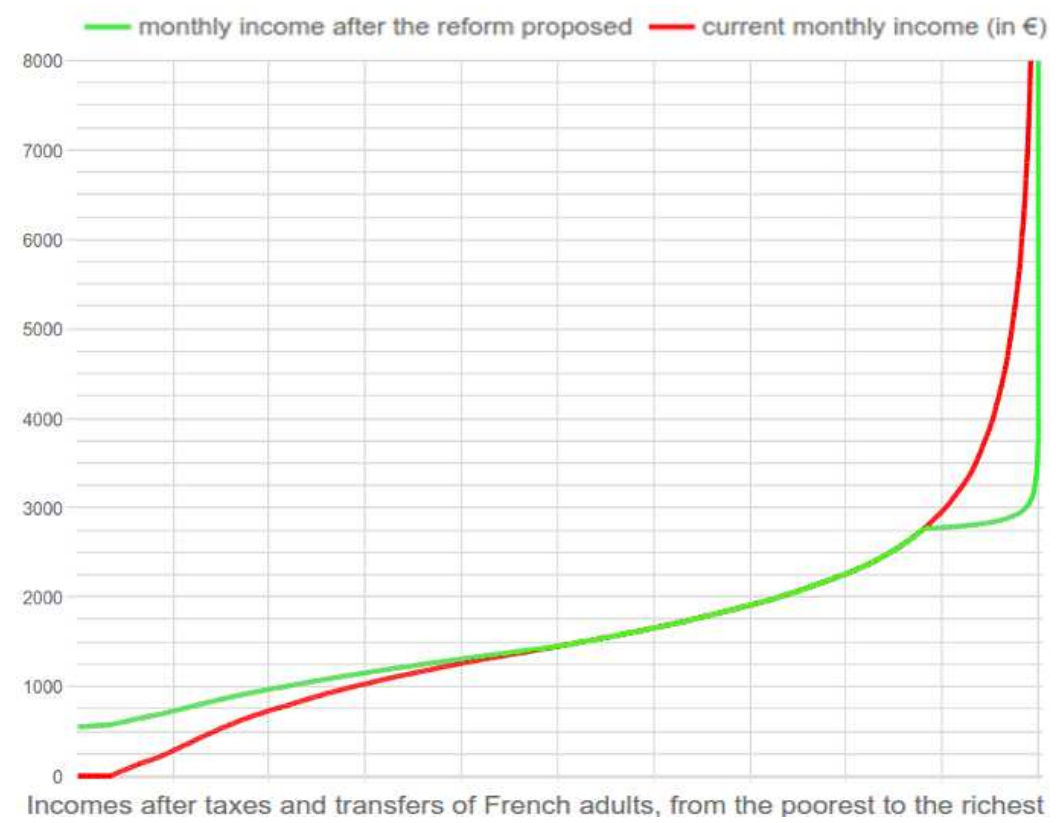

Your after-tax income is estimated at [computed] $€ /$ month. If this reform were taking place, your after-tax income would become [computed] $€ /$ month.

Would you approve such a reform?

The proposed reform was displayed below this text, followed by three options: Yes, No and PNR (I don't know, I don't want to answer). The characteristics (square brackets in the above text) for each proposed redistribution are presented in Annex $\mathrm{C}$, as a matter of fact the transfer was $10.5 \pm 1.2 \%$ of GDP in each case. In addition to the four redistributions described above that were presented in the second survey, the approval of a personalized redistribution was inquired in the first survey. This redistribution was derived from each respondent's previous answers using the Demogrant algorithm (and Extent $=5$ ).

Furthermore, a question asked the respondents to grade in $\llbracket-2 ;+2 \rrbracket$ (from I don't like... to I like this repartition) the distributions of equivalised household disposable income presented in Figure 9. as well as the personalized redistribution. Each household's equivalised income was retrieved from its members' individual disposable income and its number of consumption units 24 As one can see in Annex $\mathrm{B}$, the respondents were guided to properly understand the distributions and the question, although the distributions were not labeled. Besides, the derivation of distributions from the theory of optimal taxation was carried out using the model and source code of Jacquet et al. (2013) 25 , adapted to French data with no extensive margin.

\section{Main Results}

\subsection{Majority Adhesions to Proposed Redistributions}

Of the five redistributions proposed to the respondents, each obtained more approvals than disapprovals (see Table 2). One of them, the median proposed reform, obtained a majority of approvals taking account of non-answers, and two-thirds of approvals when excluding these $P N R$ answers. Overall, the most successful algorithm is Dis/adv: even with a national income diminished of $5 \%$ (which proxies the distortions), this algorithm outperforms the others.

\footnotetext{
24 A dataset of 5000 households was extracted from the original 128000 individuals database to make computations on each respondent's computer. Several random extractions were drawn, and the one that fitted the best the original distribution was retained.

25 This model computes the optimal nonlinear tax using an elasticity of labor supply of 0.25 to account for the equity-efficiency trade-off, in a manner similar to the seminal Saez (2001). I am indebted to Étienne Lehmann for having graciously provided me the code.
} 
Fig. 9: Distributions of equivalised disposable income presented for grading, in $€ /$ month

(a) Demogrant median

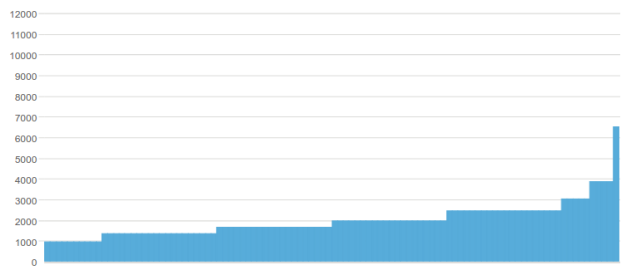

(c) Egalitarian

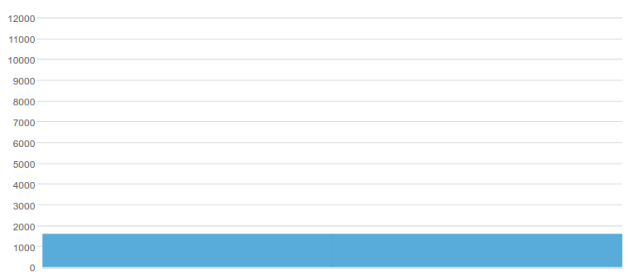

(e) Rawlsian optimal taxation

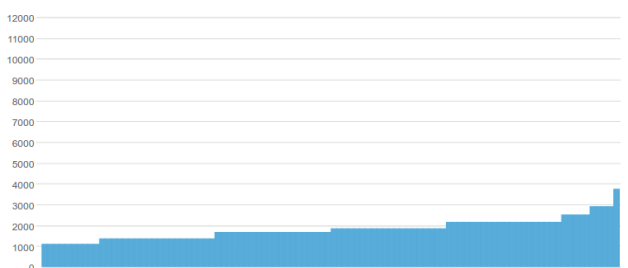

(b) Median

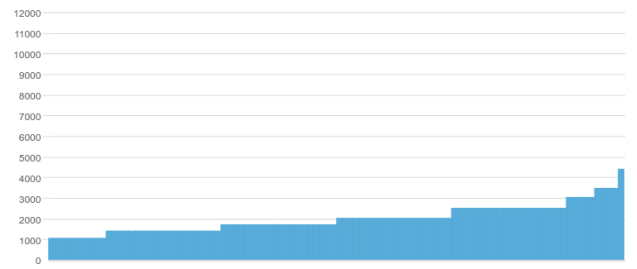

(d) Utilitarian optimal taxation

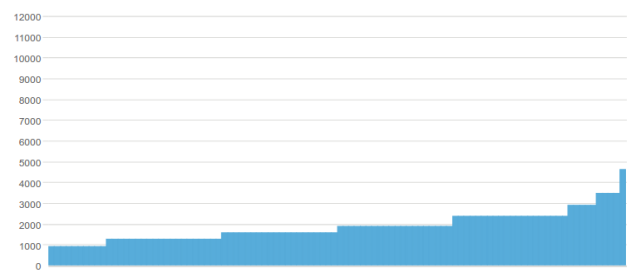

(f) Actual

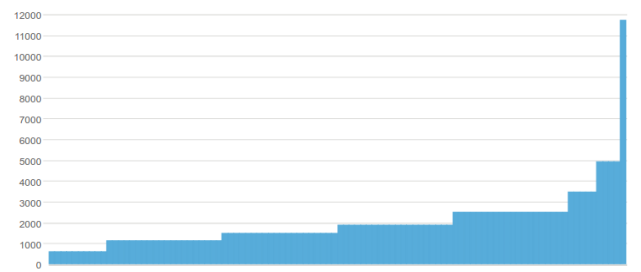

Table 2: Rate of approval of different proposed redistribution (in \%), 95\% confidence intervals are reported inside square brackets

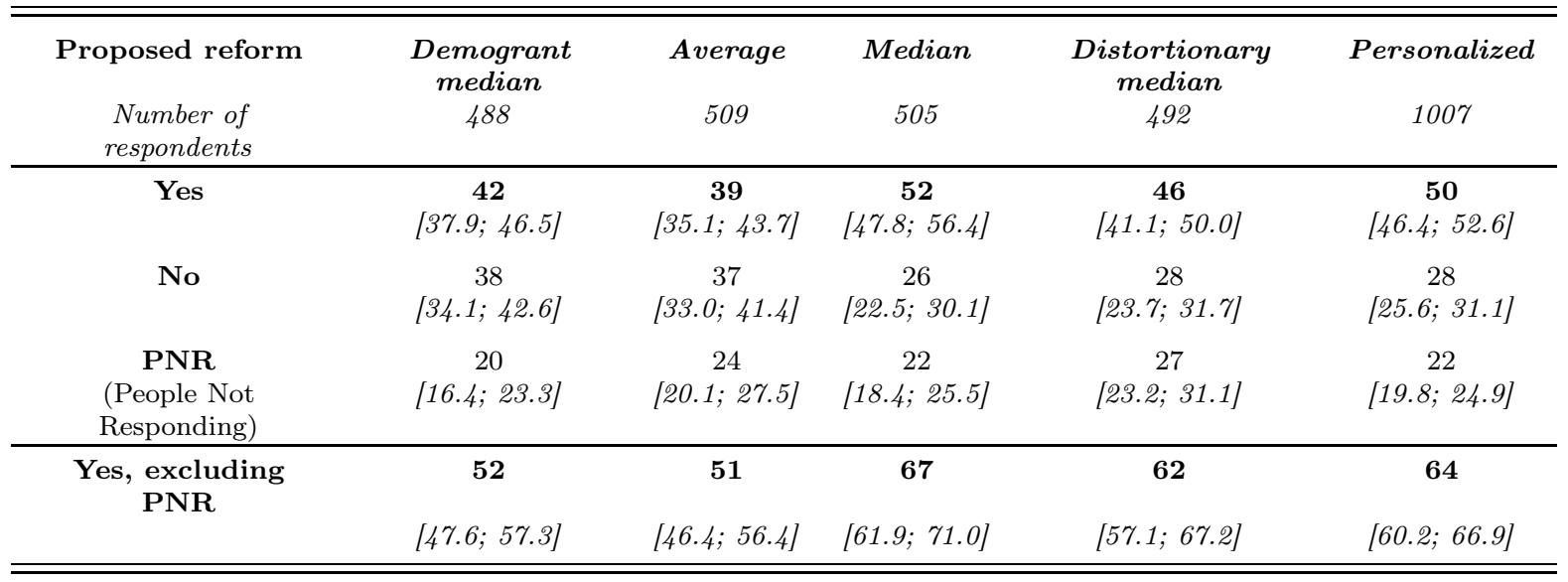

\subsection{Socio-demographic Determinants and Other Correlations}

The correlations found between a redistributive taste and socio-demographic characteristics are in line with existing literature (see Fabre (2016) for a review). In particular, the negative relationship between income and preferences for redistribution is retrieved: on average, an additional thousand euros in monthly income is associated with a $3.8 \%$ lower rate of approval when controlling for political leaning $(4.9 \%$ without this control). That being said, as one can see in Table 3. preferences remain mainly idiosyncratic: $R^{2}=0.05$ at best, while education and gender are not significantly correlated with the approval of a redistribution. Unsurprisingly, the variable that explains the highest part of the variance is the political leaning. Moreover, being indeterminate in 
one's political leaning 26 is associated with a higher propensity not to answer as well as a higher rate of approval (see Table 12 in Appendix F).

Besides, it is worth noticing that the $56 \%$ who claimed to have understood the graphical questions without trouble were more prone to approve the reform by 9 percentage points (with a high significance). However, this correlation is entirely explained by a lower rate of non-answer (see Table 16 in Appendix G).

Table 3: Socio-demographic determinants for approval of redistributive reforms (OLS) (Coefficients of dummies for missing regressors have been omitted.)

\begin{tabular}{|c|c|c|c|c|}
\hline & \multicolumn{4}{|c|}{ Approval of the reform } \\
\hline & $(1)$ & $(2)$ & $(3)$ & $(4)$ \\
\hline Constant & $\begin{array}{c}0.496^{* * *} \\
(0.031)\end{array}$ & $\begin{array}{c}0.515^{* * *} \\
(0.029)\end{array}$ & $\begin{array}{c}0.576^{* * *} \\
(0.036)\end{array}$ & \\
\hline Variant: Average & & & & $\begin{array}{c}0.499^{* * *} \\
(0.070)\end{array}$ \\
\hline Variant: Median & $\begin{array}{c}0.129^{* * *} \\
(0.031)\end{array}$ & $\begin{array}{c}0.085^{* * *} \\
(0.032)\end{array}$ & $\begin{array}{c}0.103^{* * *} \\
(0.034)\end{array}$ & $\begin{array}{c}0.600^{* * *} \\
(0.073)\end{array}$ \\
\hline Variant: Distortionary & $\begin{array}{l}0.059^{*} \\
(0.032)\end{array}$ & $\begin{array}{c}0.018 \\
(0.033)\end{array}$ & $\begin{array}{c}0.041 \\
(0.034)\end{array}$ & $\begin{array}{c}0.535^{* * *} \\
(0.072)\end{array}$ \\
\hline Variant: Demogrant & $\begin{array}{c}0.027 \\
(0.031)\end{array}$ & $\begin{array}{l}0.0003 \\
(0.032)\end{array}$ & $\begin{array}{c}0.010 \\
(0.032)\end{array}$ & $\begin{array}{c}0.506^{* * *} \\
(0.071)\end{array}$ \\
\hline Income $(\mathrm{k} \in \text { per month })^{a}$ & $\begin{array}{l}-0.049^{* * *} \\
(0.010)\end{array}$ & & $\begin{array}{c}-0.038^{* *} \\
(0.017)\end{array}$ & $\begin{array}{l}-0.010 \\
(0.047)\end{array}$ \\
\hline Income $^{2}$ & & & & $\begin{array}{l}-0.007 \\
(0.008)\end{array}$ \\
\hline Left - Right leaning $(-2$ to +2$)$ & & & $\begin{aligned}-0.072^{* * *} & (0.012)\end{aligned}$ & $\begin{aligned}-0.077^{* * *} & (0.014)\end{aligned}$ \\
\hline Left - Right ${ }^{2}$ & & & & $\begin{array}{c}0.010 \\
(0.013)\end{array}$ \\
\hline Disadvantaged & & $\begin{array}{l}-0.123^{* * *} \\
(0.025)\end{array}$ & $\begin{array}{l}-0.056 \\
(0.041)\end{array}$ & $\begin{array}{l}-0.065 \\
(0.041)\end{array}$ \\
\hline Misunderstanding of graphics & & $\begin{array}{c}-0.105^{* * *} \\
(0.022)\end{array}$ & $\begin{array}{c}-0.099^{* * *} \\
(0.022)\end{array}$ & $\begin{array}{c}-0.090^{* * *} \\
(0.023)\end{array}$ \\
\hline Wealth $(0$ to 6$)$ & & & & $\begin{array}{l}-0.009 \\
(0.011)\end{array}$ \\
\hline Future wealth (0 to 6$)$ & & & & $\begin{array}{c}0.010 \\
(0.012)\end{array}$ \\
\hline Age (1 to 8$)$ & & & & $\begin{array}{l}0.012^{*} \\
(0.007)\end{array}$ \\
\hline Gender: female & & & & $\begin{array}{l}-0.019 \\
(0.023)\end{array}$ \\
\hline Highest diploma (0 to 6 ) & & & & $\begin{array}{c}0.007 \\
(0.007) \\
\end{array}$ \\
\hline Observations & 1,994 & 1,994 & 1,994 & 1,994 \\
\hline $\mathrm{R}^{2}$ & 0.021 & 0.030 & 0.050 & 0.482 \\
\hline
\end{tabular}

a The variable used is the individual disposable income capped at $4500 € /$ month. This trimming corresponds to the top $5 \%$ of the distribution and helps getting relevant coefficients for incomes, given that the effect above $4500 € /$ month. is relatively flat and uninteresting.

A variable disadvantaged was constructed for each variant of the reform proposed: it is a dummy taking the unitary value when the individual disposable income of a respondent indicates that s-he will be disadvantaged by the reform. Being disadvantaged by a reform is associated with a significantly lower propensity to approve it, although this does not capture all the effects associated with a higher income. Overall, advantaged respondents are $12 \%$ more likely not to answer and $13 \%$ more likely to approve a reform ( $+25 \%$ excluding non-answers, see Table 4$)$. Whatever the reform, the rate of $55 \%$ of approval separates the categories of incomes advantaged and disadvantaged by the reform.

\footnotetext{
26 The respondents could choose their orientation(s) among a five-steps scale from extreme-left to extreme-right and among other orientations such as "nationalist" or "humanist". $59 \%$ of them chose at least one category on the five-steps political spectrum. The most extreme category was retained for people who declared themselves into several categories.
} 
Table 4: Approval of a reform by (individual disposable) income level (in $\%$ and $€ /$ month.), excluding people not responding (PNR)

(The cells in bold correspond to those supposed to be disadvantaged by the reform. Adv-dis corresponds to the difference between the rate of approval (or non-answers) of respondents disadvantaged and advantaged by a reform.)

\begin{tabular}{|c|c|c|c|c|c|c|c|}
\hline Income $(€ /$ month $)$ & $\leq 1200$ & $\begin{array}{l}1201 \text { to } \\
1600\end{array}$ & $\begin{array}{l}1601 \text { to } \\
2200\end{array}$ & $\begin{array}{l}2201 \text { to } \\
3000\end{array}$ & $>3000$ & Any income & Adv - dis \\
\hline PNR (any reform) & 31 & 25 & 26 & 15 & 13 & 23 & 12 \\
\hline Approval (any reform) & 75 & 64 & 58 & 56 & 38 & 58 & 25 \\
\hline median & 79 & 71 & 61 & 73 & 53 & 67 & 18 \\
\hline distortionary median & 76 & 66 & 67 & 63 & 35 & 62 & 24 \\
\hline demogrant median & 69 & 63 & 58 & 49 & 26 & 52 & 27 \\
\hline average & 75 & 56 & 48 & 42 & 35 & 51 & 23 \\
\hline Number of obs. (average) & 66 & 66 & 86 & 68 & 92 & 378 & \\
\hline Number of weighted obs. (average) & 71 & 69 & 81 & 64 & 79 & 364 & \\
\hline
\end{tabular}

\subsection{Evaluations of Distributions: Triumph of the Optimal Taxation Theory}

Figure 10 shows the results at the evaluation of distributions. While the totally egalitarian distribution is the only one that is less appreciated than the current one; the distributions that obtain the best grades under most criteria are derived from the theory of optimal taxation, using either a Rawlsian or a utilitarian criterion. This demonstrates the desirability of this theory: not only it produces solid justification for a formula of income tax rates, but it also outperforms competing propositions under popular evaluation. Moreover, it does so irrespective of the ethical criterion chosen, which does not significantly change the average grade. Interestingly, the demogrant median obtains slightly better results at the evaluation although the median reform gets the highest rate of approval. This may be due to the exposition of the current distribution along with the proposed one in the approval question, which revealed to the respondents the higher proportion of disadvantaged people in the demogrant median than in the median reform. Indeed, the spread between rates of approval among those who are disadvantaged by the demogrant median but not by the median reform is $9 \%$ higher than among the whole sample (even though the low number of observations prevents a statistical significance). Finally, it is worth noticing that the respondents tend to better grade redistributions derived from an external source (be it a theory or the aggregation of preferences) than from their own figures: it suggests that in this particular case, collective wisdom overcomes personal intelligence.

Fig. 10: Evaluation of different distributions of income

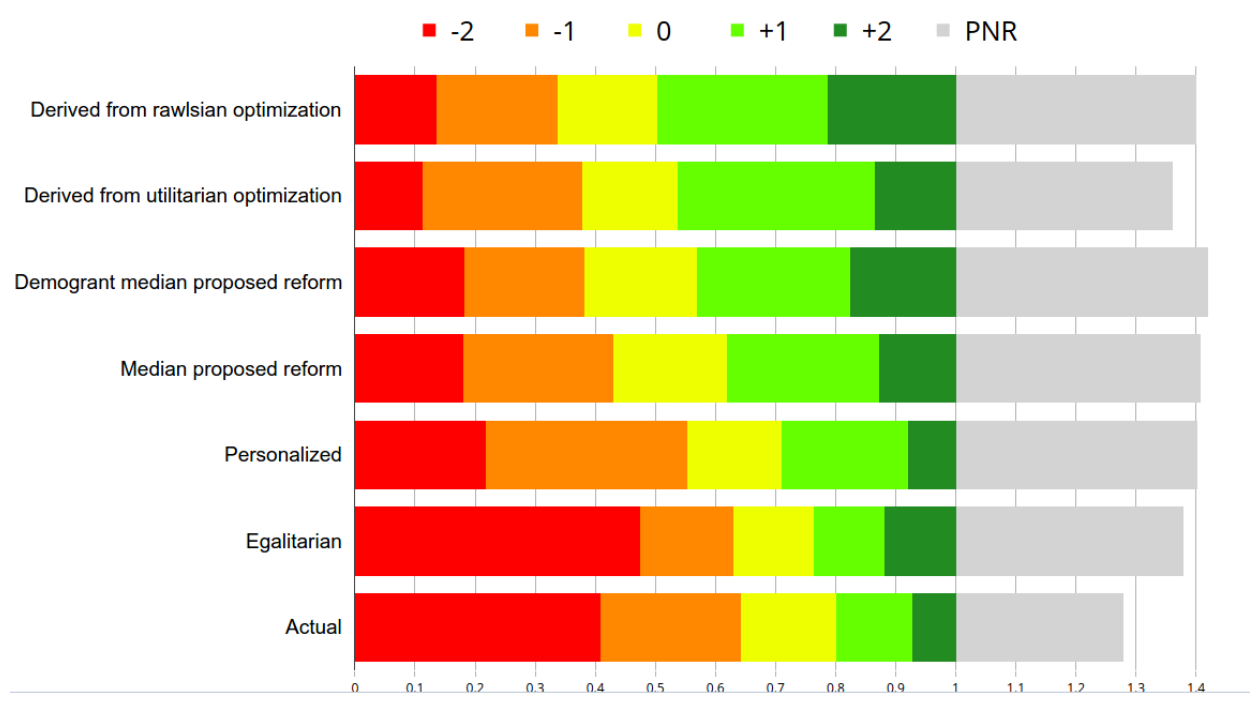




\subsection{A Surprising Link With the Theory of Optimal Taxation}

This survey has produced an unexpected result: as one can see on Figure 11, the average proposed redistribution has a shape very similar to the one derived from utilitarian optimization 27 Although the reason for this sameness is unclear, an interesting finding can be deduced using this resemblance: the rate of approval of the optimal utilitarian reform. Assuming that it would equal the one of the average reform, it would not be significantly higher than $50 \%$ even excluding missing answers, making this redistribution more controversial than the median one. Indeed, the derivation of the optimal utilitarian reform lacks of political acceptability considerations (in the same manner of averaging of people's preferences), whereas the construction of the median reform embeds some insight from political theory - namely, the median voter theorem 28 through its use of median preferred parameters and through the choice of the parameters - notably the proportion to disadvantage.

Yet, the optimal utilitarian distribution obtains a good evaluation, surpassing all proposed reforms (see section 2.3). Interestingly, this shows that in a situation closer to the veil of ignorance-because the impact of the reform on their income was not displayed, people tend to value what is socially optimal (according to the theory of optimal taxation), while they tend to favor their self-interest when the latter is made clear. Indeed, excluding missing answers, $58 \%$ of the respondents disadvantaged by the reform (proxied by those who have an individual disposable income greater than $1600 € /$ month) disapprove the average redistribution although the proportions of each grade in their evaluation of the optimal utilitarian reform are the same $( \pm 1 \%)$ as in the whole sample (their average grade is even higher by 0.06); and this effect is exacerbated for smaller subsets (resulting in $65 \%$ of disapproval and an average grade higher by 0.14 for those earning more than $3000 € /$ month).

Fig. 11: Comparison between the average and the optimal utilitarian reforms

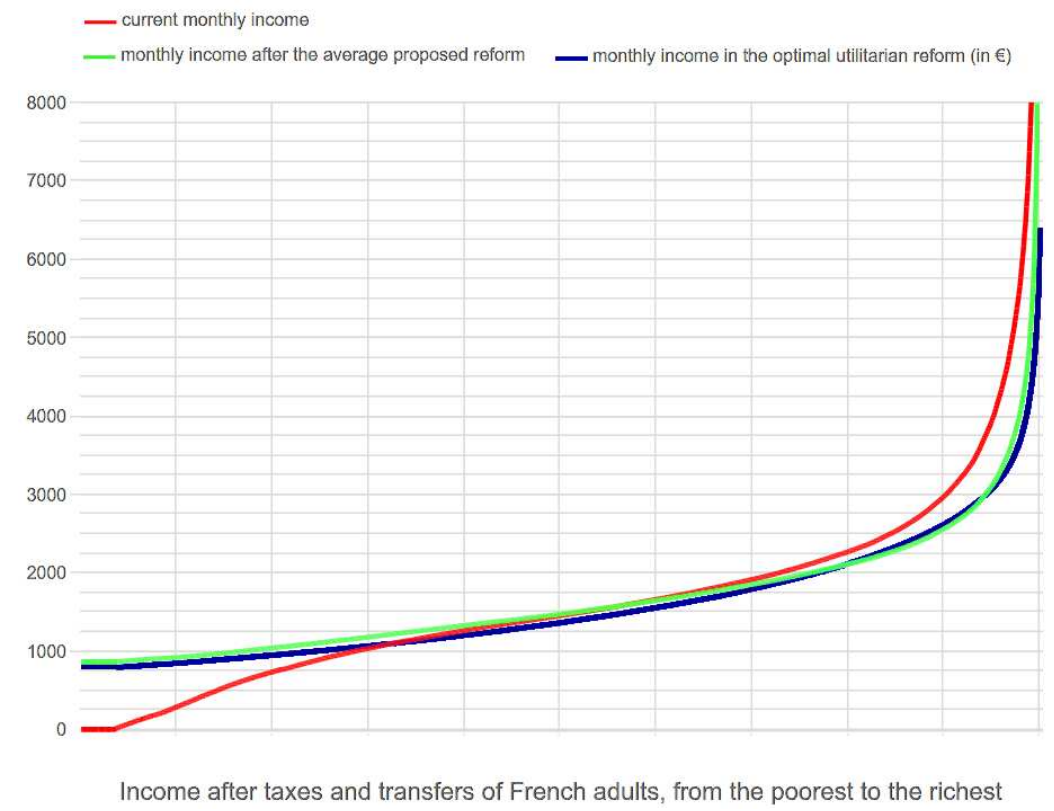

\section{Discussion}

\subsection{Robustness of the Setting}

There are several ways to prove the robustness of the results exposed in the last section, both internal (by processing the data differently) and external (by comparing these findings with previous literature). Both internal and external validity is demonstrated in Appendix G through four robustness checks: including screened out respondents in the sample, studying the non weighted

\footnotetext{
27 The only difference between the two lies in the average distribution being almost always above the utilitarian one, because the former does not take into account behavioral response.

28 Indeed, the average preferred proportion to disadvantage is $14 \%$, so using the median (10\%) instead allowed to propose a more acceptable reform.
} 
answers, controlling for the quality of responses, and comparing the findings with an earlier estimation of French preferences for income redistribution.

Thus, this subsection is devoted to the interpretation of the results rather than their strength. More specifically, the answers to the third survey allow to test whether the setting of the survey influenced the results. Indeed, in this last survey, each respondent answered the main question of the second survey with a new setting, randomly chosen over three variants. This shows that, although significant, the choices of the income variable and of the framing had only a moderate effect on the rate of approval of the median proposed reform, while providing more information about the reform had no significant impact. Consequently, the overall findings stand still. Nevertheless, I suggest a refinement of the procedure and algorithms for future work.

\subsubsection{Choice of the Individual Disposable Income}

The main drawback of the current method is to rely on the individual disposable income to present the income distribution. Indeed, this variable exhibits a significant number of very low incomes, including 3.5 percents of people with no income, which does not adequately corresponds to the extent of extreme poverty. The reason for this is twofold: firstly, the dataset provided by INSEE is not fully precise on the ends of the distribution 29 secondly, income is arguably better measured at the household level, because intra-household transfers often make zero-earners well-off. In effect, only $7 \%$ of people with no income had an household equivalised income below 10,000€/year: these zero-earners are most often young adults or spouses in a typical household.

To measure the bias introduced by this choice of variable and learn its sign, the "singles" median proposed reform was computed for the subpopulation of childless singles above 25 years-old, and the main question was reformulated so as to refer to this subpopulation. As one can see in Figure 12a, this reform is much less substantial than those of the previous section. As is shown in Table 5. this resulted in a similar rate of approval and non-answers, but a lower rate of disapprovals: only $20.5 \%$ disagreed with this reform. If anything, showing the individual disposable income of all adults showed that French people are ready for quite a substantial redistribution, and this robustness check shows that smaller ones would be even more widely accepted.

Table 5: Rate of approval of different proposed redistribution (in \%). 95\% confidence intervals are reported inside square brackets. ${ }^{*}:<10 \%$ and ${ }^{* *}:<5 \%$ designate a rate significantly different than that of median

\begin{tabular}{ccccc}
\hline \hline $\begin{array}{c}\text { Proposed reform } \\
\text { Number of respondents }\end{array}$ & $\begin{array}{c}\text { Median } \\
505\end{array}$ & $\begin{array}{c}\text { Singles median } \\
447\end{array}$ & $\begin{array}{c}\text { Triple without info } \\
455\end{array}$ & $\begin{array}{c}\text { Triple with info } \\
451\end{array}$ \\
\hline Yes & $\mathbf{5 2}$ & $\mathbf{5 3}$ & $\mathbf{4 7 *}$ & $4 \mathbf{7}^{*}$ \\
& {$[47.8 ; 56.4]$} & {$[48.7 ; 58.1]$} & {$[42.4 ; 51.4]$} & {$[42.6 ; 51.7]$} \\
No & 26 & $21^{* *}$ & 25 & 28 \\
& {$[22.5 ; 30.1]$} & {$[17.0 ; 24.6]$} & {$[21.7 ; 29.5]$} & {$[23.9 ; 32.1]$} \\
PNR & 22 & $26^{*}$ & $28^{* *}$ & 25 \\
$($ People Not Responding) & {$[18.4 ; 25.5]$} & {$[22.2 ; 30.4]$} & {$[23.9 ; 31.9]$} & {$[21.3 ; 29.3]$} \\
\hline Yes, excluding PNR & $\mathbf{6 7}$ & $\mathbf{7 2 *}$ & $\mathbf{6 5}$ & $\mathbf{6 3}$ \\
& {$[61.9 ; 71.0]$} & {$[67.1 ; 76.9]$} & {$[59.7 ; 69.8]$} & {$[57.7 ; 67.9]$} \\
\hline \hline
\end{tabular}

\subsubsection{Framing}

In attempts to gather preferences on such a complex issue as the tax system, the surveyer tends to frame the questions from a peculiar perspective. Furthermore, the angle through which a proposal is presented is likely to bias the responses. The practical solution to overcome this issue is to multiply the surveys - preferably with different surveyers - as well as the number of persons who review them, so as to average out their different perspectives. Admittedly, the framing of my survey may have been biased towards redistribution, because it presented the reform as a redistribution, and masked the level of tax that people already pay. On the other hand, Weinzierl (2014) might have been biased towards equal sacrifice, because along the levels of after-tax income for different schedules, their graphics presented current pre-tax incomes - rather than current aftertax distribution (see Figure 13). This reflects the underlying perspective that pre-tax incomes are deserved, or at least that their distribution is more relevant to the determination of the post-reform

29 In particular, the ERFS fails to take account of the transfers from parents to their children living independently. 
Fig. 12: New settings in the third survey

(a) The single median reform, computed in the same way as the median one, but on childless singles above 25 .

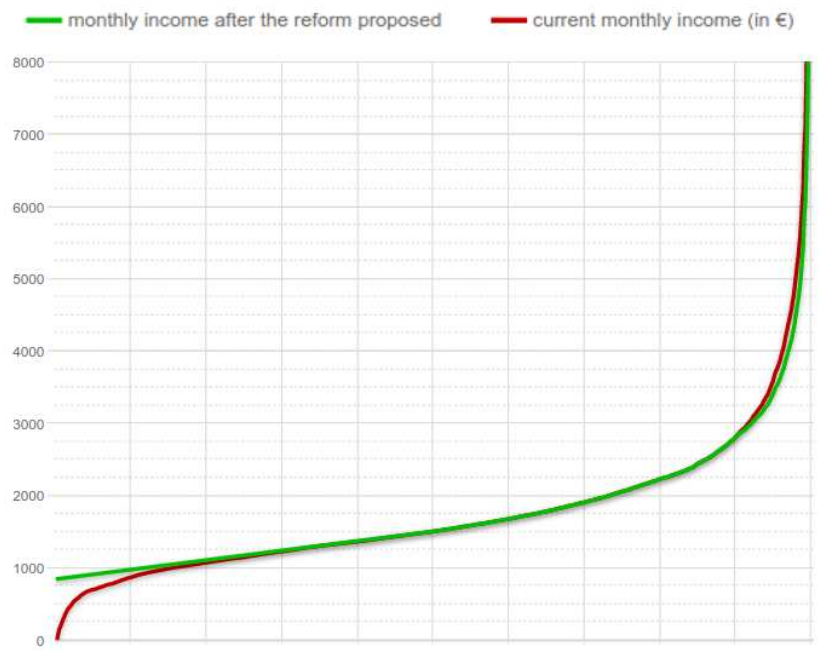

Income after taxes and transfers of French adults, from the poorest to the richest

(b) The triple median reform: the median reform where pre-tax incomes are also displayed.

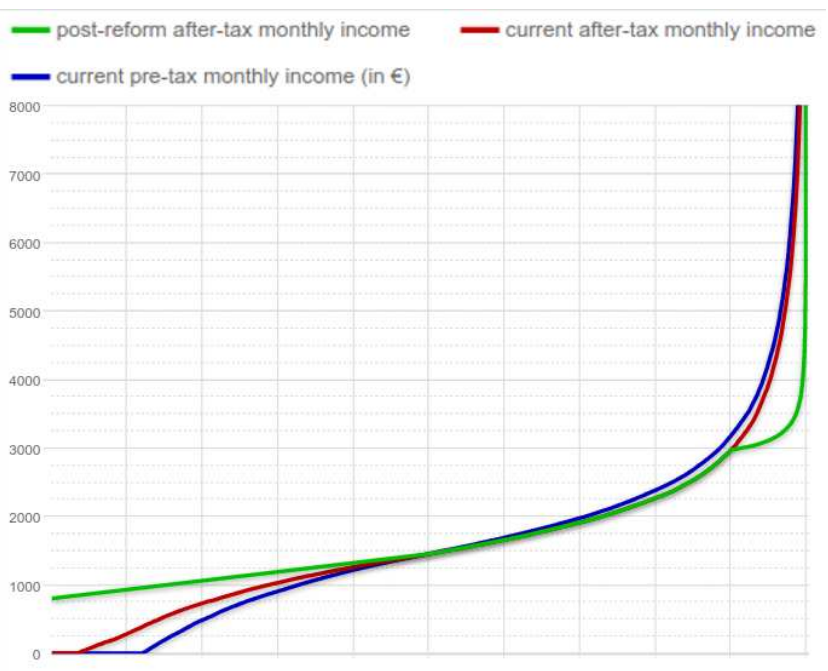

Income after taxes and transfers of French adults, from the poorest to the richest

after-tax distribution than the current after-tax distribution. In this vein, pooling the top $1 \%$ in the same rectangle veiled the extent of inequalities at the top while presenting the level of tax for each group emphasized the sacrifice made by tax-payers.

While many surveys can be questioned relatively to the perspective which they favor, letting those attempts to harvest people's preferences perfectible and incomplete, there is a way to reconcile Weinzierl's tropism with mine. One can present in the same graphic three distributions instead of two: both current pre-tax and after-tax distributions, alongside the alternative after-tax distribution. Doing this insures that those who feel that more redistribution is needed can recognize which proposal implies that feature (correcting for Weinzierl's bias) while showing the amount of existing transfers help people realizing the extent of contribution required for a reform (correcting for my bias). This framing was tested in the third survey (see Figure $12 \mathrm{~b}$ ).

The rate of approval decreased significantly by $5 \%$, but with no effect on the rate of disapproval: instead, there were more non-answers. This is understandable, as the graph becomes less readable with three curves instead of two. Excluding non-answers, the rate of approval decreased of $2.7 \%$ (with a p-value of $28 \%$ ). Overall, the small size of this effect confirms the main results of this study: a large majority of French people approve the median proposed reform, among those who have an opinion. 
Fig. 13: Example of question from Weinzierl (2014). Transparent boxes represent pre-tax income while green rectangles stand for after-tax income.
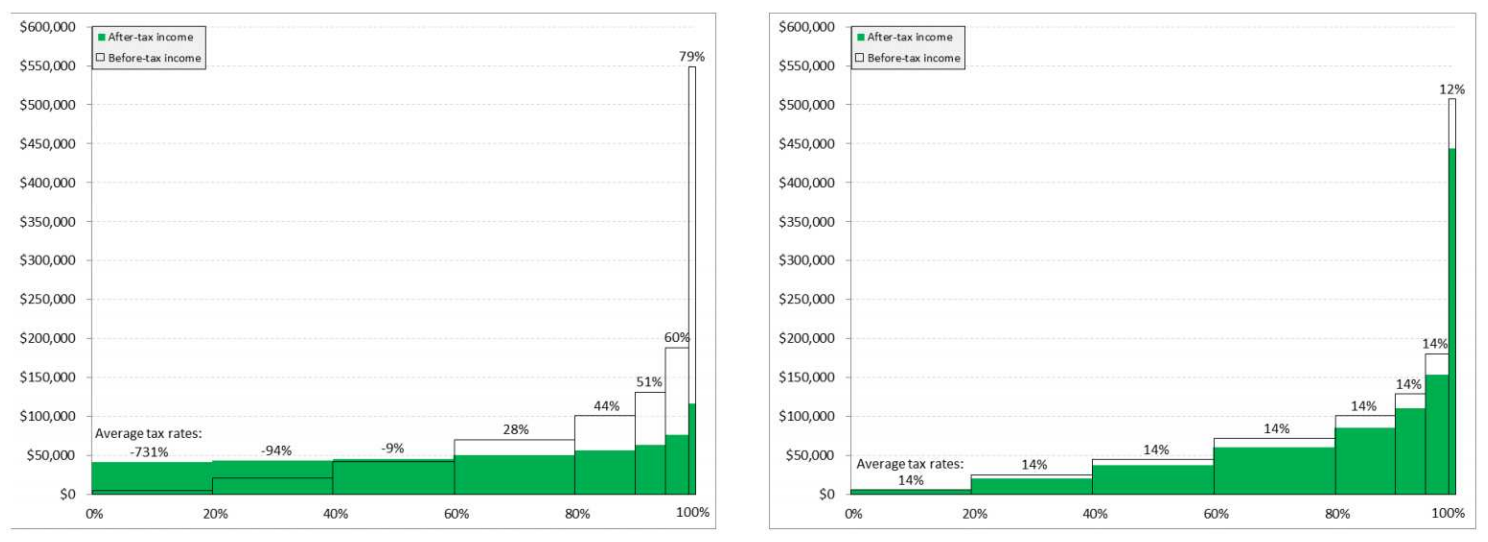

\subsubsection{Providing More Information}

Anticipating the lack of readability of the graph with three curves, more information about the reform was randomly displayed or not, consisting in describing the effect of the reform on 7 levels of income 30 However, it had no significant effect on the answers, suggesting that the graph was sufficient to understand the reform.

A similar finding emerged from the first survey, where the comparison of the respondent's (and when appropriate, of her-his household's) income before and after the reform was randomly displayed (or not) in the question on the personalized reform. There was no effect of showing the personal impact of the reform on one's answer (see Appendix F). This is why randomizing its display was no longer necessary in the second survey, where it was always shown. The absence of effect is best explained by the fact that, with the current and proposed distribution within sight, the respondents could already infer the impact of the reform on their income. Indeed, this is in agreement with the finding that the only significant effect of this treatment lies in its interaction with a lack of comprehension of the questions containing graphics: while those who struggled understanding these questions were less likely by 16 percentage points to take a side on the approval of a reform when its impact on their own income was displayed, this higher indecision reached 26 percentage points when it was not shown (see Appendix $\mathrm{F}$ ). In the third survey however, there was no significant interaction between understanding the graphics and providing more information by paraphrasing the graph.

\subsubsection{Refinement of the Method}

Several features of the income tax have been simplified in order to present a clear proposal of reform to the respondents. However, some improvements could be made to refine a reform and obtain more precise preferences:

- allow for a familial component, rather than impose an individualized system;

- take into account the number of hours worked 31

- distinguish different situations from the benchmark redistribution, such as: capital income, imputed rents, unemployment, retirement, students, or even gender or profession 32 (cf. results on this in Appendix (C);

- choose the budgetary cost of the reform 33

- include the amount of the minimum wage as a fourth parameter of the reform.

\footnotetext{
30 More specifically, the 7 examples given were: $800 \rightarrow 950 ; 1,100 \rightarrow 1,130 ; 1,500 \rightarrow 1,500 ; 2,800 \rightarrow 2,800 ; 3,000 \rightarrow 2,950$; $4,000 \rightarrow 3,700 ; 5,000 \rightarrow 4,500 ; 20,000 \rightarrow 16,000 €$ /month.

31 Indeed, it may seem unfair that someone working full-time for $2000 € /$ month would not be advantaged by the (current) proposed reforms, contrarily to someone working half-time for the same hourly wage. Saez and Stantcheva (2016) provide survey evidence on this question.

32 For the latter, a distinction could be made between civil servants and people employed by the private sector, or for jobs in a particular condition, such as farmers or entrepreneurs, etc.

33 Each respondent could propose a new budget by lowering or increasing each public spending (and possibly also revenues), and the answers could then be averaged to determine the budget of the reform.
} 
This last point seems at the same time easy to accommodate and important to fit better the citizens' preferences. Indeed, the desired amount for the minimum wage was asked in the third survey, and a large agreement was found on the median answer of 1,500€, which corresponds to an increase of $13 \%$ of the disposable of minimum wage earners 34 (see Figure 14, and Appendix C for raw data). One would have to modify the algorithms proposed in order to incorporate these preferences, because in their current form their focus on the demogrant impedes to target precisely the minimum wage.

Fig. 14: "What should be the French legal minimum income after taxes and transfers, for a single person above 25 working full-time?" (in $€ /$ month, 1353 observations)

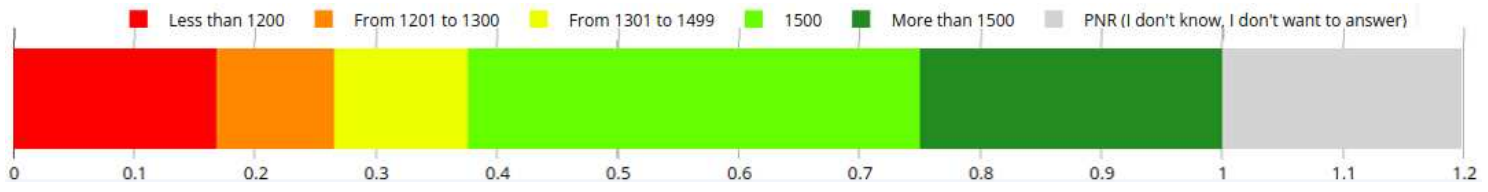

\subsection{Democratic Choice of a Redistribution}

\subsubsection{A New Democratic Process to Choose Income Tax Rates}

While French citizens are dissatisfied with the current distribution of incomes resulting from the tax system, this article provides a proof of concept for a new democratic process to choose income tax rates, whose outcome would likely better fit citizens' preferences. This process would contain several steps:

1. The parliament would command a survey aimed at determining the features and parameters of a reform favored by the citizens. The method presented in this article improved by the remarks of the section 3.1.4 would constitute a good candidate.

2. The national statistics bureau would administer the survey and expose the results publicly.

3. The reform that best suits respondents' preferences would be put to a referendum.

4. In case of success of the first steps, the tax reform would be progressively implemented.

A redistribution likely to transfer one tenth of income from the richest to the poorest would entail a substantial restructuring of the economy through the re-allocation of consumption across sectors (at least, for the sectors with a high homogeneity in their customers' incomes). In order to smooth the re-organization of the economy, as well as to let enough time for rich indebted people to deleverage before their incomes decrease, any large reform should be staggered over a dozen of years or so. Not only would this progressive implementation of a reform be needed to smooth the transition, but it would also help improving previsions concerning behavioral responses and the associated definition of tax rates.

Importantly, the process described above should not be carried out only once; rather, it may be repeated every one, two or three years, in order to readjust dynamically the reform according to changes in preferences. Indeed, preferences are likely to change as society would learn about its own behavioral response to the redistribution.

In addition, although the median redistribution is widely supported, it cannot be considered as the preferred redistribution of French people: one can still administer a new survey, with a new algorithm, and find a more favored redistribution. In that sense, this method of using a survey to reveal favored redistribution only provides an heuristic solution to the elicitation of the most accepted reform. Its strength lies instead in its success in exhibiting politically palatable redistributions. That being said, if successive governments were to use this property at regular intervals to shape a redistribution from survey answers and put it on referendum, the iterative process would likely converge towards a politically stable distribution: i.e. one for which no redistribution would be preferred 35

\footnotetext{
34 The net monthly minimum wage for a full-time job is at 1,170€ in France in July 2018, to which one should add $155 €$ of prime d'activité for a single person, a social aid similar to the EITC in the US. Thus, for the archetypal single person, the legal minimum earning is $1,325 € /$ month.

35 From a theoretical point of view, if each citizen can rank distributions in a non-evolving pre-order, the democratic process converges to the Smith set, i.e. the smallest non-empty set of distributions such that each distribution defeats every distribution outside the set in a pairwise comparison. Then, the iterations could diverge if and only if the Smith set contains a cycle, e.g. three distributions $A, B, C$, with $A \prec B, B \prec C$ and $C \prec A$, where $X \prec Y$ denotes that a majority approves the reform from $X$ to $Y$.
} 
Finally, French people seem open to such a process. Indeed, the respondents of the first survey were asked whether the tax rates should be determined from a survey and then put on a referendum (see Figure 15). Interestingly, 44\% approved the idea, while only $14 \%$ were satisfied with the current system. The high share of people dissatisfied by both the current system and the new method $(29 \%)$ calls for new ideas regarding the democratic determination of the income tax schedule as well as for a deeper analysis of the features desired in the decision process. Such an analysis was undertaken in the third survey (see Figure 16). Each step of the democratic process described above was agreed by a strict majority of respondents (i.e. even including non-answers). Yet, $74 \%$ chose not to answer to at least one of the five questions. Among those who expressed an answer to each of them, $53 \%$ chose 'Yes' to each of the new steps and 'No' the status quo, confirming an approval of the proposed process of the same magnitude than in the first survey (51\%, when one excludes non-answers). Finally, although this paper is only a first and incomplete attempt to find a consensual democratic process for the definition of the tax system, it already elicits a decision process approved by a majority, whose outcome is also approved by a majority.

Fig. 15: "What do you think of determining the income tax schedule preferred by the citizens in a survey, and submitting this outcome to a referendum?" (1007 obs.)

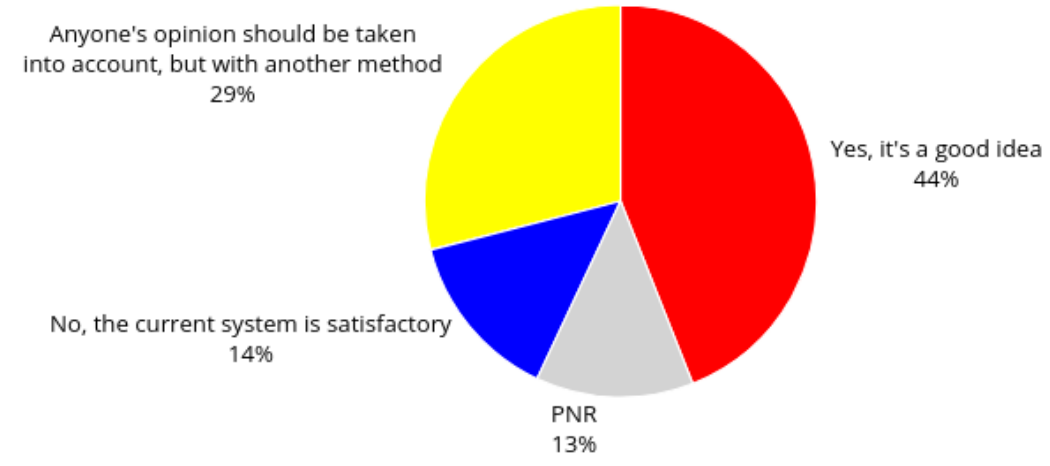

Fig. 16: Opinions concerning the decision process of determination of income tax rates (1353 observations)

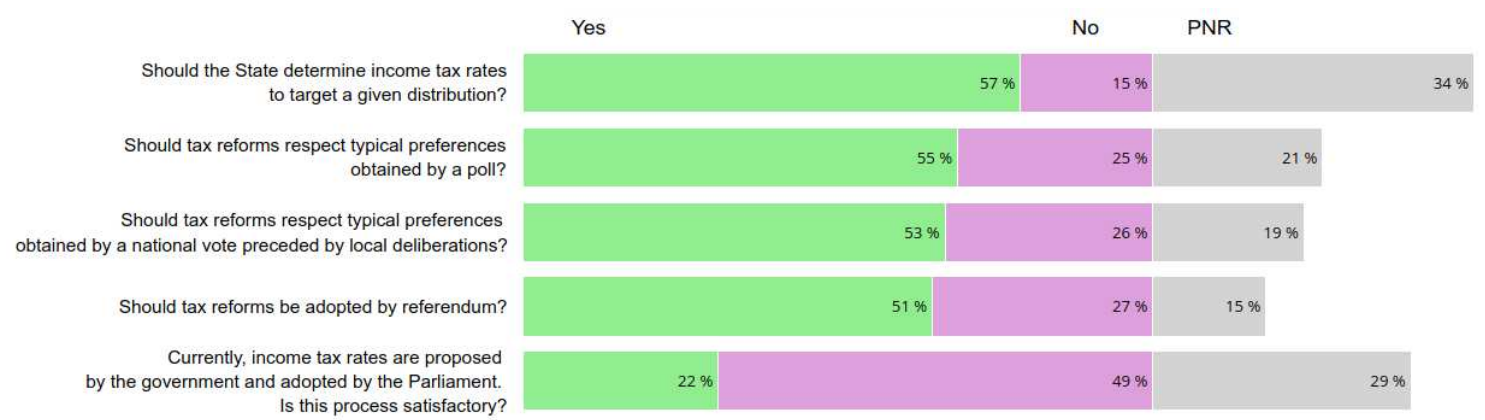

\subsubsection{Avoiding the Tyranny of the Majority}

One may be worried that the process described in the previous subsection could lead to the tyranny of a majority, hence would not entail a most desirable distribution. To address this issue, one can enrich the voting procedure and sharpen the criterion of acceptation of a redistribution. For example, taking ground on the theory developed by Balinski and Laraki (2007), one can ask respondents to grade the current and proposed redistributions between -2 and +2 , and use this information in a more sophisticated rule to select the most accepted redistribution. Balinski and Laraki argue that the most desirable aggregation of preferences consists in electing the proposition with the highest grade at the $k$-th quantile in its grades' distribution 36 (this notably overcomes

\footnotetext{
36 Ties are resolved by ranking the propositions $c$ according to the following formula: $g_{c}+\mathbb{1}_{p_{c}>q_{c}} p_{c}-\mathbb{1}_{p_{c} \leq q_{c}} q_{c}$, where $g_{c}$ is the $k$-th quantile of $c$ 's grades and $p_{c}$ (resp. $q_{c}$ ) is the proportion of grades strictly above (resp. strictly below) $g_{c}$.
} 
Arrow's impossibility theorem and minimizes manipulability). Whereas they defend the majority judgment, which relies on the the median $(k=1 / 2)$ and minimizes the gain of strategic voting, in our case one could prefer to use a lower percentile, say the first quartile, so that least satisfied people get more influence on the final decision. Combining several criteria would further hamper a possible tyrannical reform of a majority by favoring the status quo. For example, one could require that for a reform to pass, the new distribution would need to obtain a super-majority of approvals (e.g. at least $60 \%$ of expressed answers), to be better graded than the incumbent distribution by the first quartile, and to win the majority judgment among redistributions satisfying these two first criteria.

Using the evaluation of actual and proposed distributions by the respondents between -2 and +2 , one can assess if this more conservative three steps process would lead to a redistributive reform or not. Although the distributions derived from optimal tax theory were not tested for approval in the survey, section 2.4 suggests that they wouldn't have won a super-majority approval. As the median reform is the only reform to obtain a super-majority of approvals, it is the only one tested that meets the first criterion defined above. As is shown in Table 6, it also fulfills the two other criteria. Therefore, this proposed redistribution provides a robust basis for a redistribution of French incomes.

Table 6: Evaluation statistics of different income distribution

(The distributions in bold were tested in the second survey (997 respondents) while the others were tested in the first one (1007 respondents), except for the actual distribution, which was tested in both. See note 36 for the definition of the score's formula and Balinski and Laraki (2007) for that of the majority gauge.)

\begin{tabular}{ccccc}
\hline & \multicolumn{2}{c}{ Score at $k$-th quantile } & Majority & Average \\
& $k=0.25$ & $k=0.5$ & gauge & grade \\
\hline Rawlsian optimum & -0.337 & 0.497 & $0+$ & 0.237 \\
Utilitarian optimum & -0.379 & 0.464 & $0+$ & 0.108 \\
Demogrant median & -0.381 & 0.431 & $0+$ & 0.043 \\
Median & -0.43 & -0.43 & $0-$ & -0.104 \\
Personalized & -0.554 & -0.554 & $-1+$ & -0.403 \\
Actual & -1.408 & -1.408 & $-1-$ & -0.782 \\
Egalitarian & -1.475 & -1.475 & $-1-$ & -0.752 \\
\hline \hline
\end{tabular}

\subsection{Computations of the Income Tax Rates}

The proposed redistributions were until now expressed in terms of shift in the after-tax distribution. However, were such redistributions set in place, the social planner would have to infer the new income tax rates needed to attain them, taking due account of behavioral responses. I will present hereafter two ways of doing this: an empirical one that can be used during the process of the reform, and a theoretical one, which allows to define the income tax rates ex ante.

\subsubsection{Empirical and Dynamical Computation}

The first approach is agnostic about the determinants of the behavioral response $\rho=\Delta z$ that a one-period redistribution triggers on the pre-tax distribution $z$. Following a change in tax rates $\Delta T_{t}^{z}=T_{t}^{z}-T_{t-1}^{z}$, the after-tax distribution also varies, by $\Delta c_{t}=c_{t}-c_{t-1}$. Hence, the subsequent aggregate change in pre-tax distribution is borne by a change in tax revenues and in aggregate disposable income: $\int \rho=\int \Delta T+\int \Delta c$. If the response $\rho$ is well anticipated, the reform can be made budget neutral (i.e. $\int \Delta T=0$ ), so that the entire loss due to the response is absorbed by an adjustment in the objective of redistribution $\Delta c$. In theory, the social planner could use the first year of a progressive implementation of the reform to learn $\rho$, and then adjust its objective of redistribution for the following years (e.g. to respect budget neutrality). However, the response has no reason to be linear, and will inevitably change as the reform is adjusted. Thus, the learning of the response is a permanent process, which can be described formally for each quantile $q$ of the distribution as an expression of the intended (or objective of) redistribution $\mathbf{E}[\Delta c(q)]$, the expected change in tax distribution $\mathbf{E}[\Delta T(q)]$ and the expected response $\mathbf{E}[\Delta \rho(q)]$ : 


$$
\begin{aligned}
z_{t}=z_{t-1}+\rho_{t} & =c_{t}+T_{t} \\
& =c_{t-1}+\mathbf{E}_{t-1}\left[\Delta c_{t}\right]+T_{t-1}+\mathbf{E}_{t-1}\left[\Delta T_{t}\right]+\rho_{t}-\mathbf{E}_{t-1}\left[\rho_{t}\right]
\end{aligned}
$$

Finally, the next-period tax schedule is given by the expectation of response and the intended redistribution:

$$
\begin{aligned}
T_{t+1}(q) & =T_{t}(q)+\mathbf{E}_{t}\left[\Delta T_{t+1}(q)\right] \\
& =T_{t}(q)+\mathbf{E}_{t}\left[\rho_{t+1}(q)\right]-\mathbf{E}_{t}\left[\Delta c_{t+1}(q)\right] \\
T_{t+1}^{z}(z) & =T_{t+1}\left(\mathbf{E}_{t}\left[q_{t+1}(z)\right]\right)
\end{aligned}
$$

In the case of a linear implementation of the reform, i.e. $\mathbf{E}_{t-1}\left[\Delta c_{t}\right]=\Delta c_{t-1}$ for $t \in \llbracket 1 ; t_{\max } \rrbracket$, the response can simply be expected to be constant: $\mathbf{E}_{t-1}\left[\rho_{t}\right]=\rho_{t-1}$, and the tax schedule is easy to compute.

\subsubsection{Theoretical Approach}

One can also compute the income tax rates by using a more theoretical model. Such an approach is indeed necessary, at least to estimate the response during the first year of the reform. Furthermore, this modeling can be coupled to the algorithm which determines the intended aftertax distribution, so that behavioral responses are taken into account in the project of reform 37 Modeling the behavioral response requires to make assumptions on their determinants. Following a common practice in the applied literature (e.g. Saez (2002) or Jacquet et al. (2013)), I assume away income effects, so that the pre-tax distribution responds solely to changes in marginal tax rates 38 This behavioral effect is captured by the elasticity of earnings $z$ with respect to the net-of-tax rate $1-T^{\prime}: \zeta_{z}=\frac{1-T^{\prime}}{z} \frac{\partial z}{\partial\left(1-T^{\prime}\right)} 39$

Keeping the notations of the previous subsection, one has:

$$
\begin{aligned}
c(q, t) & =z(q, t)-T(z(q, t), t) \\
\frac{d c}{d t}(q, t) & =\frac{\partial z}{\partial t}(q, t)-\frac{\partial T}{\partial t}(z(q, t), t)-\frac{\partial T}{\partial z}(z(q, t), t) \cdot \frac{\partial z}{\partial t}(q, t)
\end{aligned}
$$

Forgetting indices for more clarity:

$$
\frac{d c}{d t}=\frac{\partial z}{\partial t} \cdot\left(1-\frac{\partial T}{\partial z}\right)-\frac{\partial T}{\partial t}
$$

Using the definition of $\zeta_{z}$, one obtains a partial differential equation for $T 40$

$$
\frac{d c}{d t}=-\zeta_{z} \cdot z \cdot \frac{\partial^{2} T}{\partial t \partial z}-\frac{\partial T}{\partial t}
$$

The discrete version of this model (which has been originally derived in Fabre $(2016)$ ) gives the semi-discrete counterpart of equation 2

$$
\Delta c=-z \cdot \zeta_{z} \cdot \Delta T^{\prime}-\Delta T
$$

Equation 3 can in turn be solved, as it is an Euler-Cauchy equation of the variable $\Delta T$; it is tractable when $\zeta_{z}$ is approximated by a linear, step or power function. In practice, the continuous version can be approximated by $N$ iterations of the discrete version: one has only to define a path $c_{k}(q)$ with $k \in \llbracket 1 ; N \rrbracket$, choosing $N$ large enough so that, for all $k, \Delta c_{k}=c_{k}-c_{k-1}$ remains small enough (so that $\Delta z_{k}$ can be considered infinitesimal). In practice however, the simulations produced almost the same results for $N=1$ and $N=10$. Finally, the Figure 17 presents the results

\footnotetext{
37 The distortionary median reform was already computed by an algorithm that takes as a parameter the expected loss due to the behavioral response. However, the value chosen for this parameter ( $5 \%$ ) was estimated separately, and the process of coupling this algorithm to a model giving the behavioral response (in order to reach convergence in the expected behavioral response) is yet to be done.

38 Other consequences of the reform on the activity would possibly occur, such as an increase in aggregate demand following the redistribution due to a higher marginal propensity to consume of the poor; but they are not modeled.

39 Let us precise that $T^{\prime}=\frac{\partial T}{\partial z}$.

40 I recall that other functions than $T$ are known, as well as the initial condition $T(\cdot, 0)$.
} 
obtained by applying this model to the median reform with a constant elasticity of labor supply, set to a credible value of 0.3 (see e.g. Gruber and Saez 2002; Evers et al. 2008; Chetty 2012 for empirical estimates). As expected, pre-tax incomes decrease through the effect of the reform, by an average of $7.4 \%$ (while magnitudes of $5.3-7.6 \%$ are observed for the other proposed reforms).

Fig. 17: Simulation of behavioral responses

Variation of pre-tax distribution in the median reform, for $\zeta=0.3$

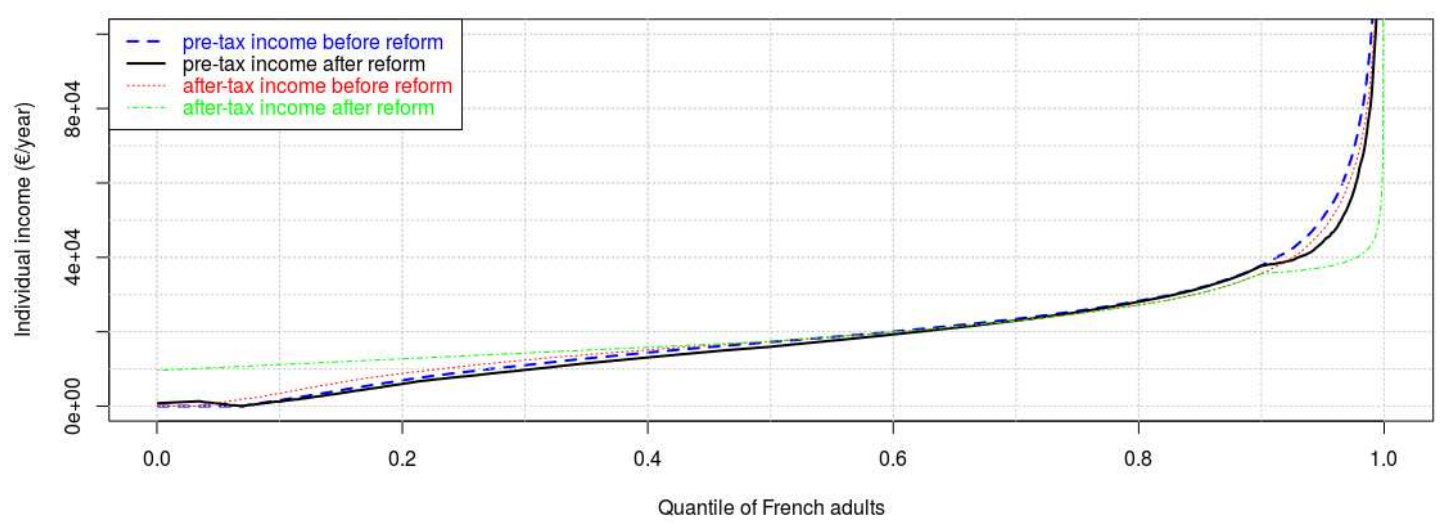

\section{Conclusion}

While the theory of optimal taxation proves very successful in determining socially optimal tax schedules, it usually relies on ad hoc assumptions about the utility function of agents and on external principles of social justice. Auspiciously a recent work by Saez and Stantcheva (2016) demonstrates that these premises did not need to remain arbitrary, by means of introducing generalized social welfare weights which can be calibrated through surveys. However, a last practical frailty of this theory needed to be examined: the political acceptability of its recommendations. Following Saez and Stantcheva in their exploration of new methods to define a desirable tax schedule, I departed from the theory and elicited some redistributions that French citizens would approve, by asking them directly for their parameters. As one of the reform proposed to the respondents appeared to resemble closely that resulting from utilitarian optimization, it could be shown that, even if it was positively appreciated in a context mimicking the veil of ignorance, this reform failed to obtain a significant majority approval when the impact on the respondent's income was made clear. This provided evidence that, for reasons of political acceptability, tax policies might have to deviate from the theoretical optimum to take into account the proportion of people disadvantaged by a reform. Combining this parameter with three others - the proportion of people to advantage, the demogrant and the extent of the redistribution - allowed to characterize a broad class of reforms with a minimal amount of information. Eventually, the redistribution defined by the median desired value for these parameters obtained the support of two-thirds of expressed answers. This result opened the way to the proposal of a participatory process that would modify progressively the French income tax system, associating recurrent surveys to shape iterative reforms and referendums to validate them. Indeed, the respondents broadly supported a more democratic procedure to choose the income tax rates 41 However, as a primary attempt to quantify a favored redistribution from survey answers, this work leaves room for significant improvements, in particular to refine the algorithm used to delineate the curves and to include more dimensions of choice.

41 Only $14 \%$ were satisfied with the current (parliamentary) process. 


\section{References}

Balinski M, Laraki R (2007) A theory of measuring, electing, and ranking. PNAS 104(21):87208725, DOI 10.1073/pnas.0702634104

Bargain O, Dolls M, Neumann D, Peichl A, Siegloch S (2014) Comparing inequality aversion across countries when labor supply responses differ. International Tax and Public Finance 21(5):845873

Bourguignon F, Spadaro A (2012) Tax-benefit revealed social preferences. J Econ Inequal 10(1):75108, DOI 10.1007/s10888-010-9153-0

Brehm JW (1966) A theory of psychological reactance. A theory of psychological reactance, Academic Press, Oxford, England

Chang BH, Chang Y, Kim SB (2017) Pareto weights in practice: A quantitative analysis across 32 OECD countries. Review of Economic Dynamics DOI 10.1016/j.red.2017.08.002

Chetty R (2012) Bounds on Elasticities With Optimization Frictions: A Synthesis of Micro and Macro Evidence on Labor Supply. Econometrica 80(3):969-1018, DOI 10.3982/ECTA9043

Evers M, Mooij RD, Vuuren DV (2008) The Wage Elasticity of Labour Supply: A Synthesis of Empirical Estimates. De Economist 156(1):25-43, DOI 10.1007/s10645-007-9080-z

Fabre A (2016) International Preferences for Income Distribution: Evidence from ISSP, 1987-2009. $\mathrm{PhD}$ thesis, Paris School of Economics

Fleurbaey M, Maniquet F (2017) Optimal income taxation theory and principles of fairness. CORE Discussion Papers

Forsé M, Parodi M (2015) Les Français et la justice fiscale. Revue de l'OFCE 137(1):97, DOI $10.3917 /$ reof.137.0097

Gruber J, Saez E (2002) The elasticity of taxable income: evidence and implications. Journal of Public Economics 84(1):1-32, DOI 10.1016/S0047-2727(01)00085-8

Hendren N (2014) Efficient Welfare Weights. Working Paper 20351, National Bureau of Economic Research, DOI 10.3386/w20351

Hovland CI, Janis IL, Kelley HH (1953) Communication and persuasion; psychological studies of opinion change. Communication and persuasion; psychological studies of opinion change, Yale University Press, New Haven, CT, US

Jacquet L, Lehmann E, Van der Linden B (2013) Optimal redistributive taxation with both extensive and intensive responses. Journal of Economic Theory 148(5):1770-1805, DOI 10.1016/j. jet.2013.07.019

Parodi M (2014) On peut douter de tout, mais pas avec n'importe qui ? Les questions délicates dans l'enquête post- électorale de la présidentielle de 2012. OFCE Working Paper

Piketty T (2003) Attitudes vis-à-vis des inégalités de revenu en france and : Existerait-il un consensus ? Comprendre (PUF)

Piketty T, Saez E (2013) Chapter 7 - Optimal Labor Income Taxation. In: Auerbach AJ, Chetty R, Feldstein M, Saez E (eds) Handbook of Public Economics, handbook of public economics, vol. 5, vol 5, Elsevier, pp 391-474, DOI 10.1016/B978-0-444-53759-1.00007-8

Saez E (2001) Using Elasticities to Derive Optimal Income Tax Rates. Review of Economic Studies 68(1):205-229

Saez E (2002) Optimal Income Transfer Programs: Intensive versus Extensive Labor Supply Responses. Q J Econ 117(3):1039-1073, DOI 10.1162/003355302760193959

Saez E, Stantcheva S (2016) Generalized Social Marginal Welfare Weights for Optimal Tax Theory. American Economic Review 106(1):24-45, DOI 10.1257/aer.20141362

Singhal M (2008) Quantifying Preferences for Redistribution. Unpublished

Weinzierl M (2014) The promise of positive optimal taxation: normative diversity and a role for equal sacrifice. Journal of Public Economics 118:128-142, DOI 10.1016/j.jpubeco.2014.06.012 


\section{A Summary Statistics}

Table 7: Summary statistics of reform parameters for different samples

\begin{tabular}{rrrrrrrrrrr}
\hline \hline & \multicolumn{1}{c}{ first sample restricted } & \multicolumn{3}{c}{ first sample augmented } & \multicolumn{3}{c}{ final sample (both surveys) } \\
& median & PNR & obs. & median & PNR & obs. & median & $95 \%$ C.I. & PNR & obs. \\
\hline Advantage & 50 & 175 & 449 & 50.00 & 315 & 645 & 50.00 & {$[50 ; 50]$} & 265 & 621 \\
Disadvantage & 10.0 & 206 & 500 & 10 & 357 & 699 & 10 & {$[9 ; 10]$} & 589 & 1325 \\
Demogrant & 750.00 & 77 & 253 & 800 & 151 & 369 & 738.4 & {$[700 ; 800]$} & 167 & 456 \\
Maximal income & $50 \mathrm{k}$ & 44 & 243 & $100 \mathrm{k}$ & 92 & 354 & $250 \mathrm{k}$ & {$[100 \mathrm{k} ;$ Inf $]$} & 130 & 600 \\
\hline \hline
\end{tabular}

\section{B Survey Screen Shots}

The questionnaires are available on-line:

first sample: adrien-fabre.com/sondage/Politique\%20des\%20francais.html

second sample: preferences-pol.fr/Politique\%20des\%20francais.html

Fig. 18: Disadvantage:

"On the occasion of a tax reform which would redistribute income from the richest to the poorest, what proportion of French people should be disadvantaged by the reform? What we call being disadvantaged by the reform, is incurring a decrease in one's after-tax income as compared to the current situation, and it would concern the richest French.

The slider below helps you answer the question: the text below the slider changes when you shift the slider (by maintaining the mouse pressed and shifting it on the side). The value of the slider is not recorder, thus you have to report the value you will have chosen in the field below. Among French, $20 \%$ earn more than $2450 € /$ month.

A proportion of ... should be disadvantaged (in \%):

PNR (Do not know, do not wish to answer)"

The slider is on-line: preferences-pol.fr/Fiscalite\%20des\%20francais.html\#QuestionText_q36035863_FR

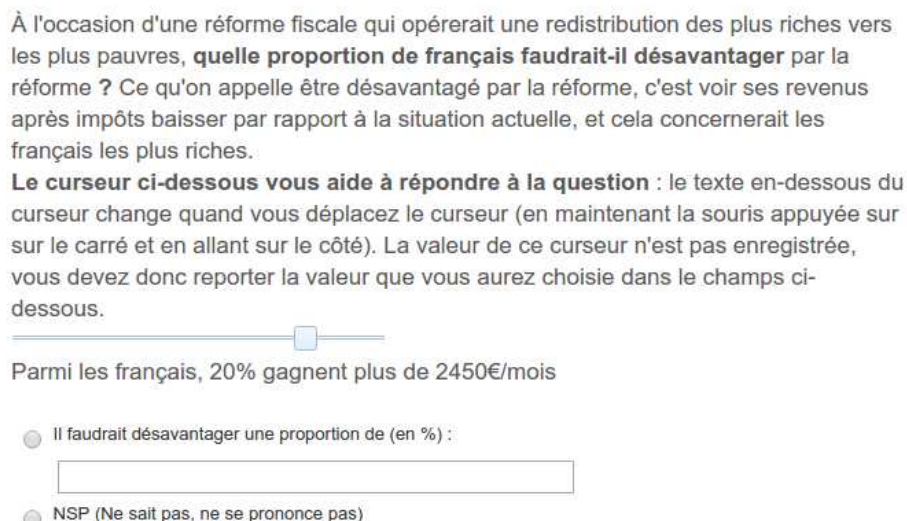


Fig. 19: Process of decision for the tax schedule

"Currently, tax rates are voted at the Parliament. This is not the only possible process: for example, it would be possible to determine the tax rates preferred by citizens in a survey, and then put the proposal that would emerge from the survey on a referendum. Do you think that citizens should be consulted in this way to determine income tax rates?

Yes, this is a good idea

No, the current system is satisfactory

We should better take into account everyone's opinion, but through another method PNR (Do not know, do not wish to answer)"

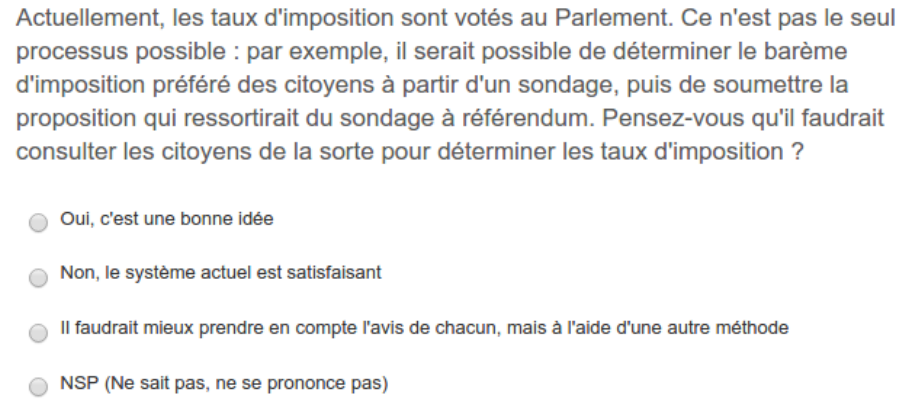

Fig. 20: Evaluations

"Three graphs representing the standards of living of French adults, from the poorest to the richest, are presented below one another. For example, according to the first graph, the richest $1 \%$ would have a standard of living of $11700 €$ per month (we can read the values of the graphs by maintaining the mouse over the blue bars). The different graphs show how the French national income can be distributed among French, in more or less egalitarian ways. According to your preferences in terms of inequalities, you can grade each graph, by a grade between -2 (I don't like this distribution) to +2 (I like this distribution): you just have to shift the slider next to each graph. It is greatly recommended to scroll until the bottom of the page to see all graphs before grading them."

Trois graphes représentant les niveaux de vie des adultes franç̧ais, des plus pauvres au plus riches, vous sont présentés les uns en-dessous des autres. Par exemple, d'après le premier graphique, les $1 \%$ les plus riches auraient un niveau de vie de $11700 €$ par mois (on peut lire les valeurs des graphiques en restant sur les barres bleues avec la souris). Les différents graphes montrent comment le revenu national de la France ('j'aime cefte réparitition) : il suffit de déplacer le curseur à cốté de chaque courbe. Il est vivement recommandé d'aller jusqu'en bas de la page pour voir tous les graphes avant de leur donner une note.

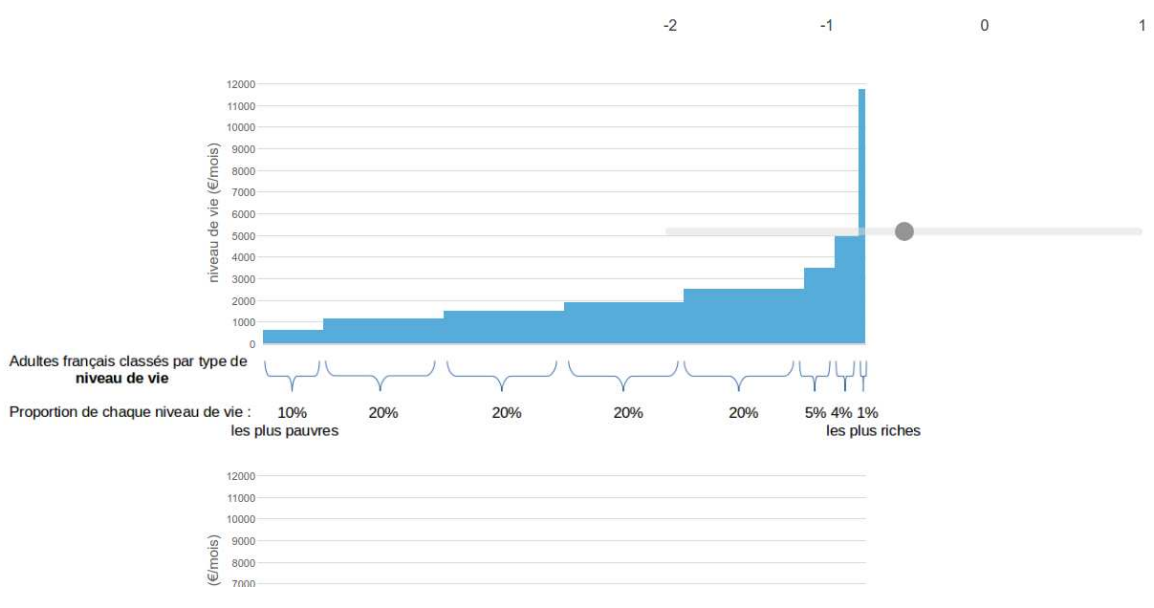


Fig. 21: Legal maximum incomes (only one version was randomly displayed, cf. section 1.2 .2 for the translation)

Si la France était une société idéale, quel serait le revenu mensuel le plus élevé ? Précisons qu'on ne demande pas ici s'il faudrait imposer une limite légale aux revenus des français : il s'agit simplement de savoir quel serait le revenu le plus élevé dans une société avec le niveau approprié d'inégalités.

Idéalement, les revenus ne dépasseraient pas (en $\epsilon /$ mois):

NSP (Ne sait pas, ne se prononce pas)

II pourrait y avoir des français infiniment plus riches que d'autres dans une société idéale.

Selon vous, quel est le revenu maximal qui devrait être instauré légalement en France? (revenu net par mois)

Le revenu maximal devrait être de (en $\epsilon /$ mois):

On ne devrait pas instaurer de revenu maximal en France

NSP (Ne sait pas, ne se prononce pas)

Selon vous, quel est le revenu maximal qui devrait être instauré légalement en France ? (revenu net par mois) II peut être utile ici de rappeler qu'au-delà d'un certain seuil, l'imposition des plus riches est souvent contre-productive, puisque ces derniers partent à l'étranger ou réduisent leur activité pour éviter la hausse des taxes.

Le revenu mensuel maximal devrait être de (en $\epsilon /$ mois) :

On ne devrait pas instaurer de revenu maximal en France

NSP (Ne sait pas, ne se prononce pas) 
Fig. 22: Demogrant (only one version was randomly displayed)

1. What should be the amount of welfare for those with no income?

2. What should be the amount for the basic income in France? The basic income would be a benefit allocated to every adult without any condition (such as age or activity), in replacement of social minima (notably RSA [minimum welfare] and APL [housing benefits]).

3. What should be the minimal income guaranteed to all French people?

4. What is the minimal income that the State should insure to all, in France?

Quel devrait être le montant des aides de l'État pour les gens qui n'ont aucun revenu?

Celles et ceux qui ont pour seuls revenus les aides de l'État devraient toucher (en $€ /$ mois):

NSP (Ne sait pas, ne se prononce pas)

Quel devrait être le montant mensuel du revenu de base en France ? Le revenu de base serait une allocation versée à chaque adulte sans aucune condition (comme l'âge ou l'activité), en remplacement des minima sociaux (RSA et APL notamment).

Le revenu de base devrait être de (en $\epsilon /$ mois) :

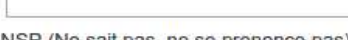

NSP (Ne sait pas, ne se prononce pas)

Quel devrait être le montant mensuel minimal garanti à tous les français ?

Le revenu mensuel minimal garanti à tous devrait être de (en $\epsilon /$ mois) :

NSP (Ne sait pas, ne se prononce pas)

Quel est le revenu mensuel minimal que l'État devrait assurer à chacun·e en France?

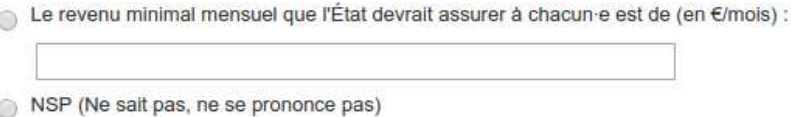




\section{Raw Results}

Fig. 23: Low incomes

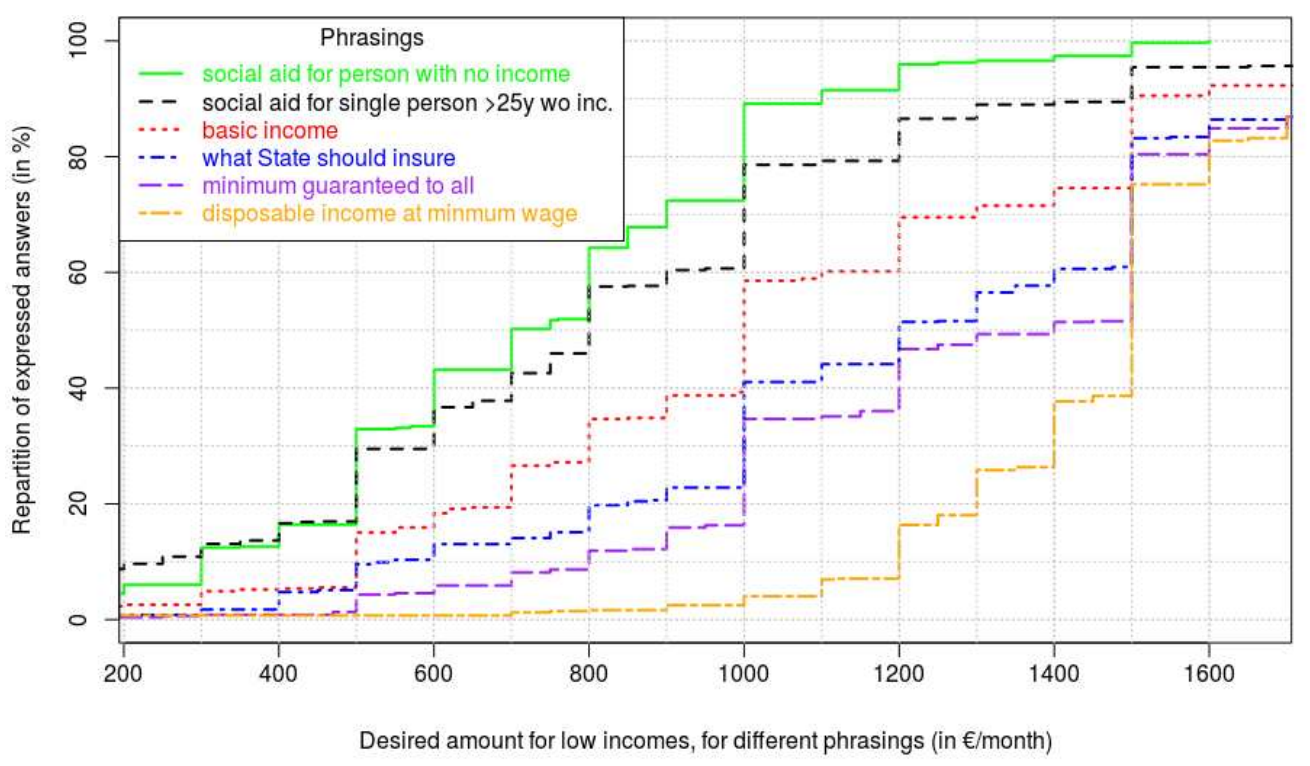

Fig. 24: Maximal income

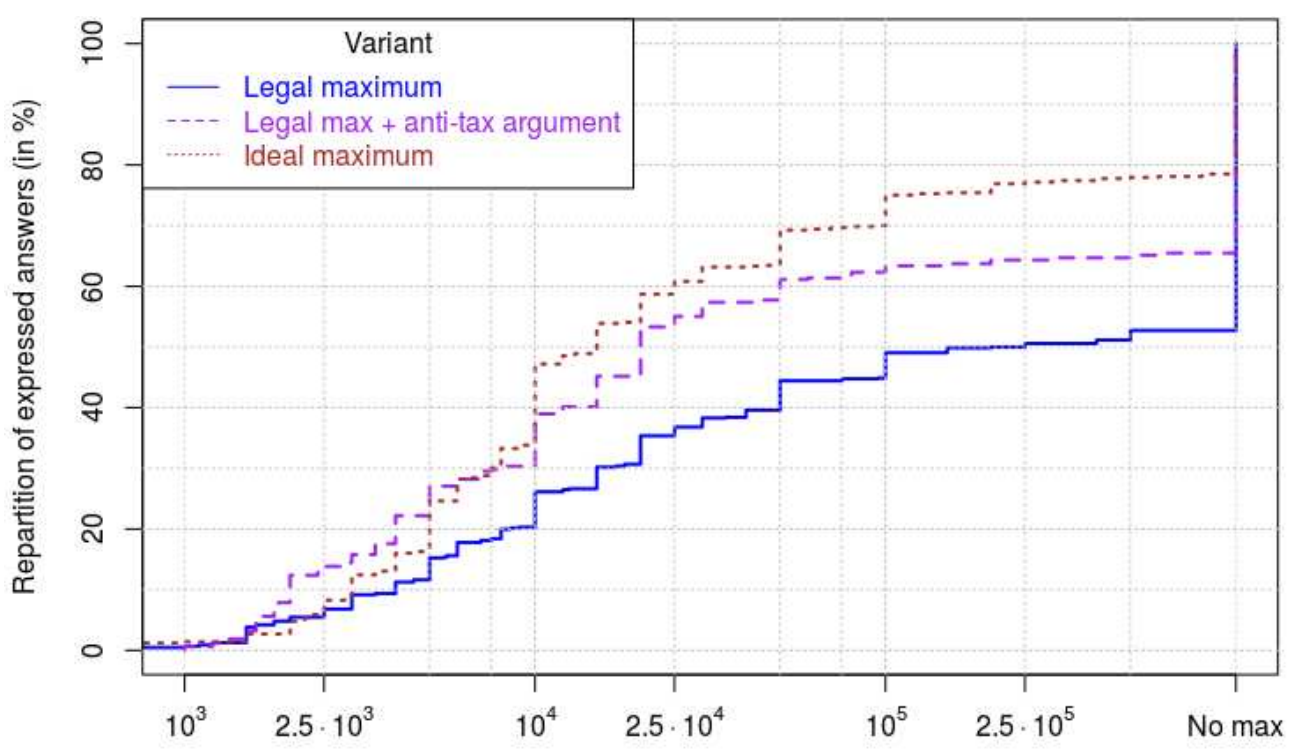

Desired amount for the maximal income, for different variants (in $€ / m o n t h, l o g s c a l e)$ 
Fig. 25: Dis/advantage

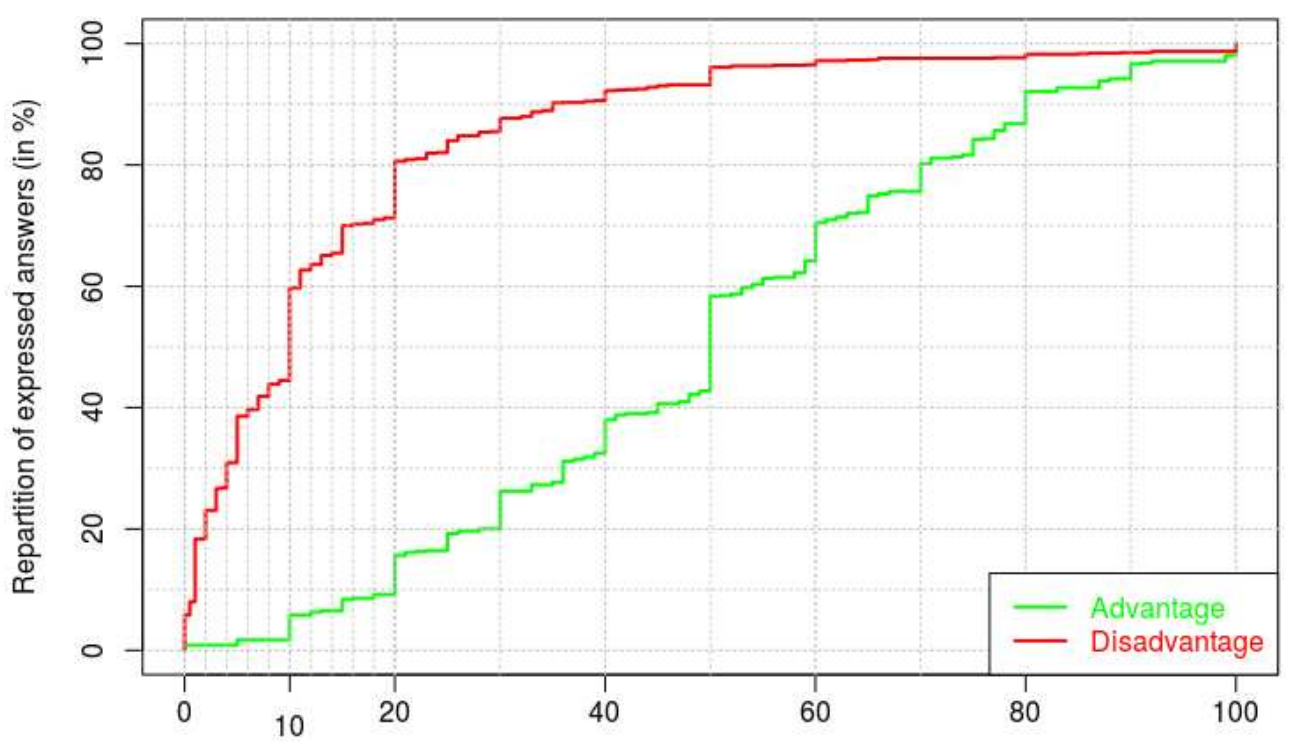

Desired proportion of people to dis/advantage through a income tax reform (in \%)

Fig. 26: Desired evolution of income for different categories

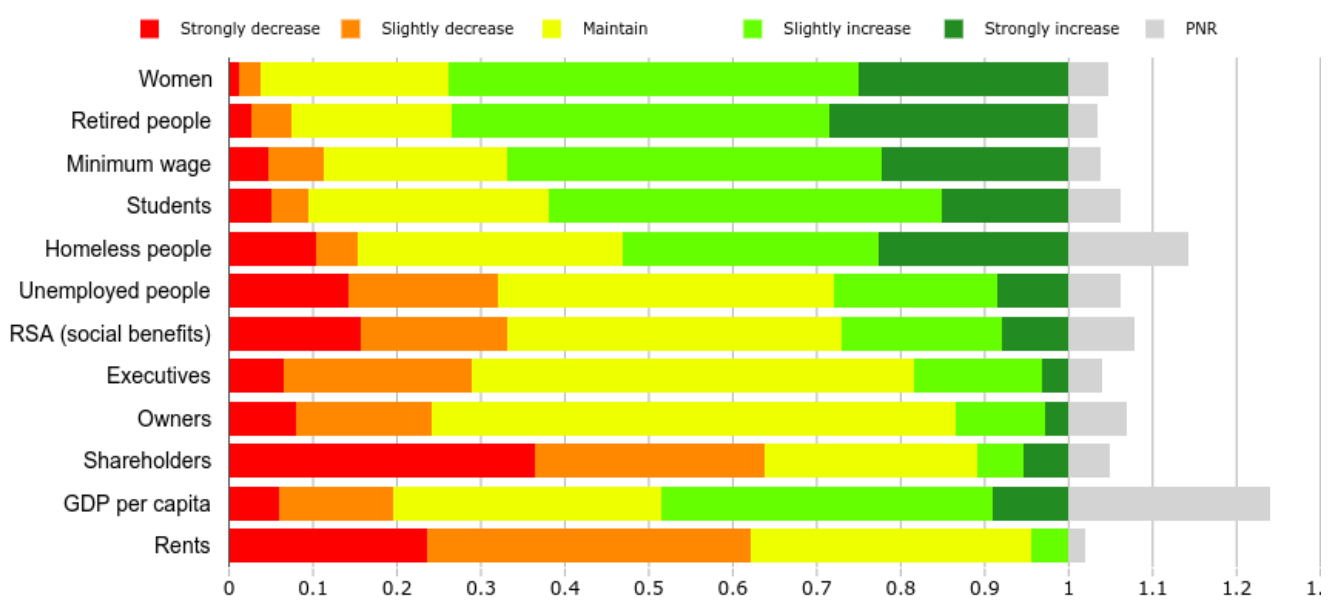

\section{Distributions Characteristics}

Table 8: Characteristics of Distributions of Income

(Dis- and Adv-stand for Dis/advantage and are expressed in \%, Demogrant is in $€ /$ month, Transfer and income shares are in proportion of GNI, and $D 9 / D 1$ is the inter-decile ratio)

\begin{tabular}{|c|c|c|c|c|c|c|c|c|c|c|}
\hline & Gini & D9/D1 & Bottom50 & Top10 & Top1 & Demogrant & Dis- & Adv- & Transfer & Extent \\
\hline equivalised disposable & 0.308 & 3.441 & 0.298 & 0.258 & 0.072 & -47 & & & & \\
\hline actual & 0.434 & 10.326 & 0.224 & 0.335 & 0.128 & 0 & & & & \\
\hline demogrant median & 0.286 & 3.101 & 0.306 & 0.242 & 0.074 & 800 & 23 & 77 & 0.094 & 3.5 \\
\hline median & 0.241 & 3.194 & 0.331 & 0.202 & 0.036 & 802 & 10 & 50 & 0.117 & 8.57 \\
\hline distortionary & 0.251 & 3.815 & 0.321 & 0.186 & 0.026 & 550 & 12 & 50 & 0.116 & 9 \\
\hline average & 0.250 & 2.797 & 0.331 & 0.224 & 0.053 & 859 & 42 & 58 & 0.117 & \\
\hline earlier median & 0.295 & 5.429 & 0.304 & 0.237 & 0.056 & 550 & 10 & 73 & 0.109 & \\
\hline
\end{tabular}


Fig. 27: Earlier estimation of median desired redistribution, from Fabre (2016)

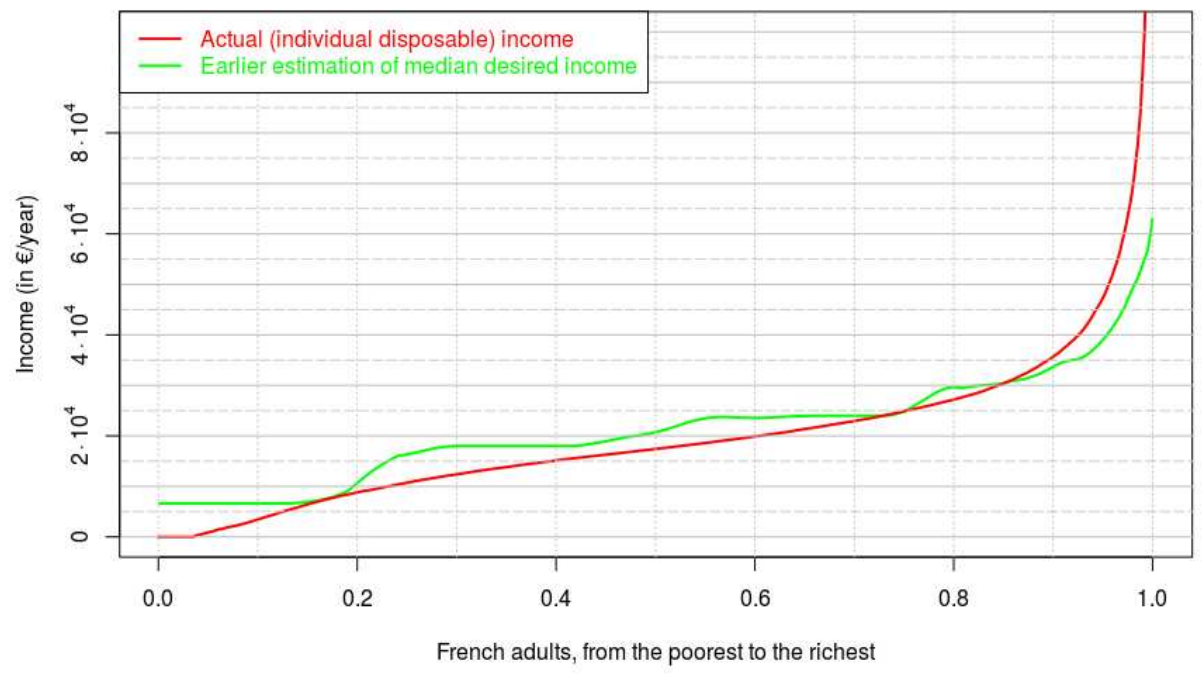

Fig. 28: Distribution of the proposed reforms in terms of equivalised disposable income (The proportions of households disadvantaged by each reform do not coincide with the points where the reforms curve crosses the current curve (because the ranking of households is not preserved). They are: $25.4 \%$ (median), 26.9\% (demogrant median), 28.6\% (distortionary median), $38.8 \%$ (average).)

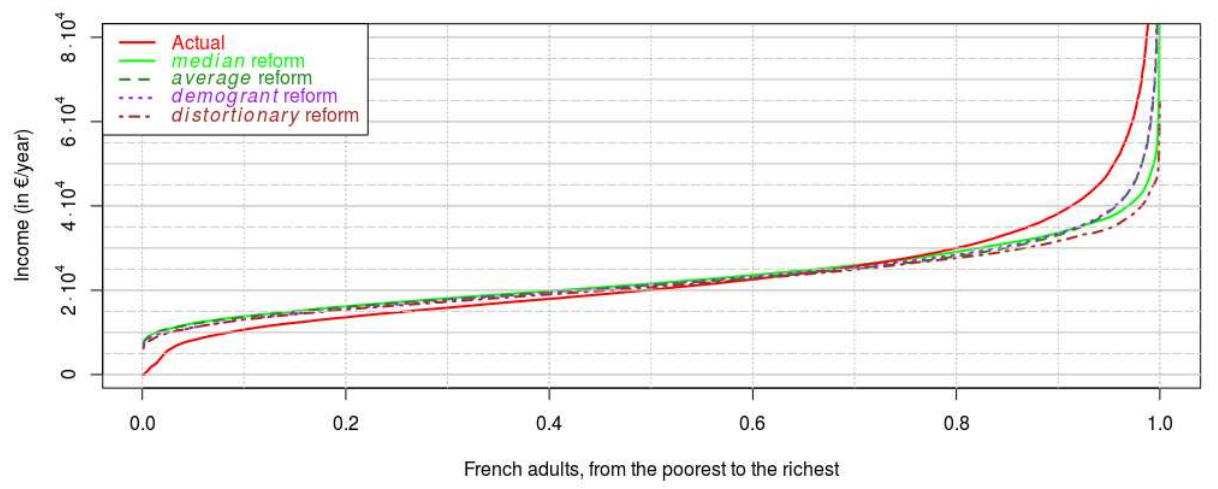

\section{E Algorithms Used}

The commented pseudo-code of the algorithms used is given on-line 42 along with a pedagogical presentation of the algorithm Dis/adv in seven slides (the main ones are presented in Figure 29). Thus, I will only summarize here the key steps of each algorithm.

Both of them start with the current distribution of income as a working distribution and make it evolved until the new distribution, using their parameters.

Algorithm Dis/adv It is worth reminding that on a range of income (concerning people that are not advantaged nor disadvantaged by the reform), both current and new distributions coincide. The algorithm proceeds in the following way:

1. define the reference curve by setting the incomes of advantaged to their maximum and those of disadvantaged to their minimum, thus drawing two horizontal lines at each end of the distribution;

2. narrow the gap between working and current distributions by a factor 1-Extent/10;

3. find the appropriate demogrant and draw a line (straight if possible) joining the demogrant to the income of the richest advantaged, so that the reform is budget neutral (absent any behavioral response);

4. decrease incomes by the amount of the loss due the behavioral response (given as a parameter), by narrowing the gaps between the working distribution and the current one (for lowest incomes) or the income of the poorest disadvantaged (for highest incomes) by a common factor.

42 http://preferences-pol.fr/doc_methode.php\#_a1 
Fig. 29: Algorithm Dis/av

(Figure 29d and 29e result in the median and distortionary redistributions)

(a) 1. reference curve

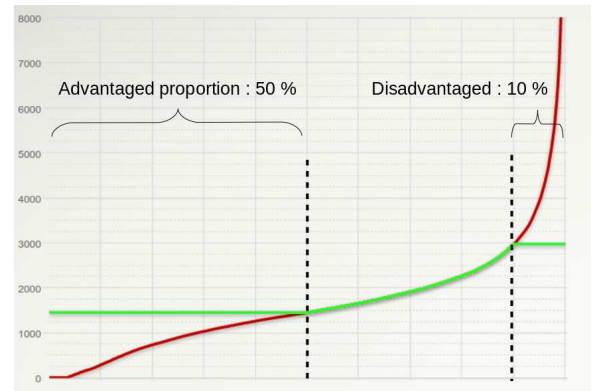

(b) 2. narrowing the gap

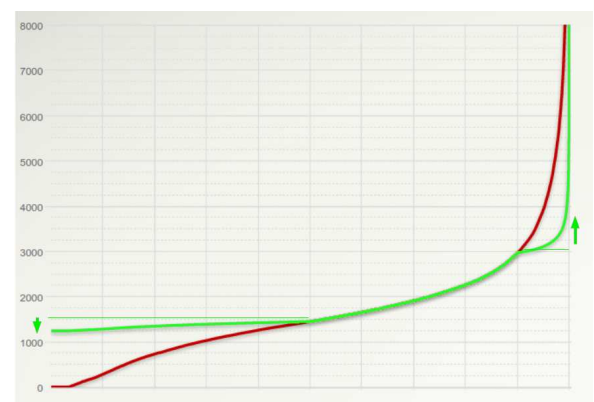

(d) 3.5 "linearize" the left end

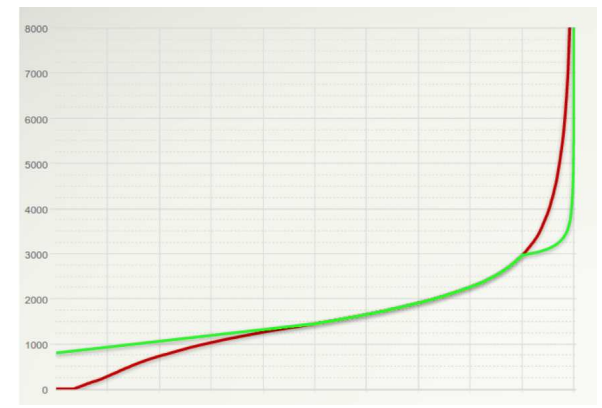

(c) 3. adjust for budget neutrality

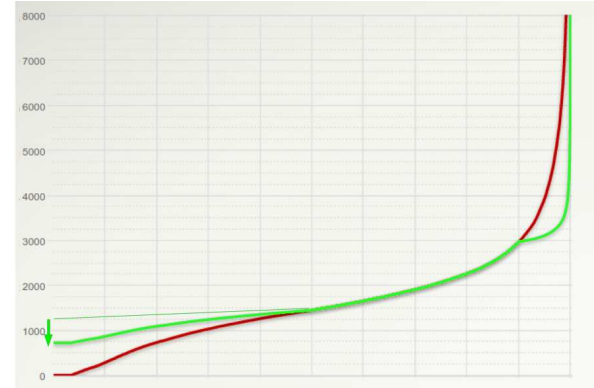

(e) 4. correct for behavioral responses

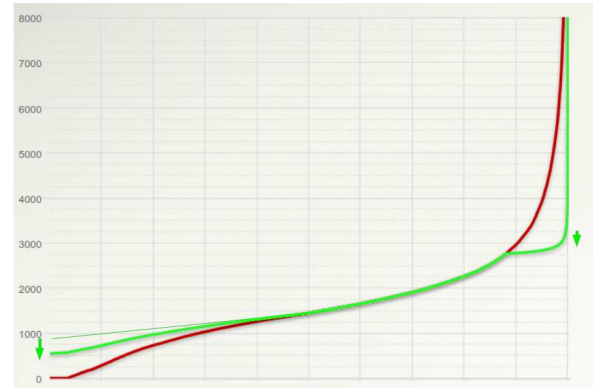

Algorithm Demogrant The algorithm Demogrant is quite baroque, because it contains many adjustments corresponding to cases for which the main steps would lead to anomalies. For the sake of clarity, I focus on the situation where the parameters allow not to deviate from the main steps. During the following sketch of these steps, the neutral point designates the point where current and new distributions cross.

1. The reference curve passes by the demogrant, is parallel with the current curve for the lowest incomes, then is straight until the neutral point, and coincides with the current curve after the neutral point; the junction between the straight line and the parallel part is set where it can be smooth.

2. The deficit $D$ is defined as the difference between the integral of the current and the reference curve. If possible, the incomes of the advantaged are decreased by an aggregate amount of $D \cdot(1-$ Extent/10), and those of disadvantaged are reduced by the appropriate amount to obtain budget neutrality (absent any behavioral response). On the left side, the gap between the reference curve and the maximum between the demogrant and the current curve is narrowed by a common proportion. On the right side, the reference curve cannot be brought closer to the neutral income by a common proportion all the way long, because the maximum income of the new curve is constrained by a parameter; but in practice, this is what happens, except for the very top quantiles of the distribution, for which a straight line is set.

\section{F Regressions}

Hereafter are reported all regressions mentioned in the article. When appropriate, Mood tests of the equality of medians were carried out; they are not reported because they produced results similar to those of linear regressions. 
Table 9: Effect of an anti-tax argument on the desired maximum income

\begin{tabular}{lcc}
\hline \hline & \multicolumn{2}{c}{$\log _{10}$ desired maximum income } \\
\cline { 2 - 3 } & Excluding infinities & Setting $\infty:=10^{9}$ \\
& $(1)$ & $(2)$ \\
\hline Anti-tax priming & $-0.221^{* * *}$ & $-0.751^{* * *}$ \\
Constant & $(0.071)$ & $(0.201)$ \\
& $4.195^{* * *}$ & $6.424^{* * *}$ \\
Observations & $(0.043)$ & $(0.113)$ \\
\hline \hline
\end{tabular}

Table 10: Effect of the choice of income variable on the proportion to dis/advantage

\begin{tabular}{lcc}
\hline \hline & Advantage & Disadvantage \\
& $(1)$ & $(2)$ \\
\hline Income expressed at household level & -1.705 & $2.500^{*}$ \\
& $(2.909)$ & $(1.354)$ \\
Constant & $50.102^{* * *}$ & $13.308^{* * *}$ \\
& $(1.430)$ & $(1.047)$ \\
\hline Observations & 356 & 736 \\
\hline \hline
\end{tabular}

Table 11: Significance of the differences in the average distributions' evaluations (with the optimal utilitarian as a reference)

\begin{tabular}{lc}
\hline \hline & Evaluation of distributions \\
\hline Optimal utilitarian (Constant) & $0.159^{* * *}$ \\
& $(0.048)$ \\
Median & $-0.140^{* *}$ \\
& $(0.069)$ \\
Actual & $-0.926^{* * *}$ \\
& $(0.059)$ \\
Demogrant median & -0.078 \\
Egalitarian & $(0.069)$ \\
& $-1.027^{* * *}$ \\
Personalized & $(0.069)$ \\
& $-0.569^{* * *}$ \\
Optimal rawlsian & $(0.069)$ \\
& 0.058 \\
Observations & $(0.069)$ \\
\hline \hline
\end{tabular}


Table 12: Effect of the display of the impact of the reform on the respondent's income, and understanding

\begin{tabular}{|c|c|c|c|c|c|c|}
\hline & \multirow{2}{*}{$\begin{array}{c}\text { Approval } \\
(1)\end{array}$} & \multicolumn{2}{|c|}{ Approval (any reform) } & \multicolumn{3}{|c|}{ Person Not Responding } \\
\hline & & $(2)$ & $(3)$ & $(4)$ & $(5)$ & (6) \\
\hline No display impact reform own income & $\begin{array}{c}-0.008 \\
(0.032)\end{array}$ & & & $\begin{array}{c}0.013 \\
(0.027)\end{array}$ & $\begin{array}{c}-0.023 \\
(0.034)\end{array}$ & $\begin{array}{l}-0.014 \\
(0.034)\end{array}$ \\
\hline Misunderstood graphics & & $\begin{array}{c}-0.095^{* * *} \\
(0.022)\end{array}$ & $\begin{array}{l}-0.014 \\
(0.030)\end{array}$ & & $\begin{array}{c}0.262^{* * * *} \\
(0.038)\end{array}$ & $\begin{array}{c}0.287^{* * *} \\
(0.044)\end{array}$ \\
\hline Political orientation indeterminate & & & $\begin{array}{c}0.090^{* * *} \\
(0.031)\end{array}$ & & & $\begin{array}{c}0.117^{* * *} \\
(0.036)\end{array}$ \\
\hline Pol. indeterminate \& Misunderstood & & & $\begin{array}{c}-0.186^{* * *} \\
(0.045)\end{array}$ & & & $\begin{array}{c}-0.097^{*} \\
(0.056)\end{array}$ \\
\hline Misunderstanding \& No display & & & & & $\begin{array}{c}-0.103^{*} \\
(0.055)\end{array}$ & $\begin{array}{c}-0.094^{*} \\
(0.054)\end{array}$ \\
\hline Constant & $\begin{array}{c}0.531^{* * *} \\
(0.023) \\
\end{array}$ & $\begin{array}{c}0.495^{* * *} \\
(0.015) \\
\end{array}$ & $\begin{array}{c}0.459^{* * *} \\
(0.020) \\
\end{array}$ & $\begin{array}{c}0.230^{* * *} \\
(0.020)\end{array}$ & $\begin{array}{c}0.165^{* * *} \\
(0.025)\end{array}$ & $\begin{array}{c}0.122^{* * *} \\
(0.028)\end{array}$ \\
\hline Observations & 958 & 1,994 & 1,994 & 958 & 958 & 958 \\
\hline $\mathrm{R}^{2}$ & 0.0001 & 0.009 & 0.018 & 0.0002 & 0.063 & 0.073 \\
\hline
\end{tabular}

Table 13: Correlation between the approval of a reform and being single without dependent child

\begin{tabular}{|c|c|c|c|}
\hline & \multicolumn{3}{|c|}{ Approval (any reform) } \\
\hline & $(1)$ & $(2)$ & $(3)$ \\
\hline Childless single & $\begin{array}{c}0.068^{* * *} \\
(0.026)\end{array}$ & $\begin{array}{c}0.062^{* *} \\
(0.026)\end{array}$ & $\begin{array}{c}0.039 \\
(0.027)\end{array}$ \\
\hline Equivalised household income ${ }^{a}$ & & $\begin{aligned}-0.046^{* * *} \\
(0.010)\end{aligned}$ & $\begin{array}{l}-0.014 \\
(0.021)\end{array}$ \\
\hline Individual disposable income ${ }^{a}$ & & & $\begin{array}{c}-0.046^{* *} \\
(0.020)\end{array}$ \\
\hline Constant & $\begin{array}{c}0.436^{* * *} \\
(0.013) \\
\end{array}$ & $\begin{array}{c}0.521^{* * *} \\
(0.022) \\
\end{array}$ & $\begin{array}{c}0.571^{* * *} \\
(0.027) \\
\end{array}$ \\
\hline Observations & 1,994 & 1,994 & 1,888 \\
\hline
\end{tabular}

$a$ The variable has been capped at $4500 € /$ month. This trimming eases the interpretation of the results and concerns $7.6 \%$ (resp. $5.4 \%$ ) of the observations in the case of the individual (resp. equivalised) income.

\section{G Robustness checks}

\section{G.1 Robustness Checks}

\section{G.1.1 Using a Broader Sample}

As explained in section 1.1 a broader sample is at our disposal. As shown in Table 14 there is a significantly lower rate of approval in this augmented sample than in our sample of reference. However, this discrepancy is entirely explained by a higher rate of non-answers: the difference vanishes when those are excluded. Furthermore, this lower proportion of non-answers is not surprising because the restricted sample excludes respondents who are likely to choose not to answer: those who responded too quickly and those who did not complete the survey. On the contrary, it indicates that the restriction of the augmented sample has been successful. 
Table 14: Approval of proposed redistributions in the augmented sample

Reading: Among the 1007 answers (on the approval of a proposed reform) in the augmented sample who were not also in the restricted sample, the approval rate was 35.3\%; it was on average 10\% higher in the restricted sample, but this effect is entirely explained by the higher share of nonanswers (columns (2) and (3)).

\begin{tabular}{lcccc}
\hline \hline & Headcount & Approval (of any reform) & Non-answer \\
& (additional) & $(1)$ & $(2)$ & $(3)$ \\
\hline In augmented (constant) & 1,007 & $\begin{array}{c}0.353^{* * *} \\
(0.015)\end{array}$ & $\begin{array}{c}0.563^{* * *} \\
(0.019)\end{array}$ & $\begin{array}{c}0.373^{* * *} \\
(0.013)\end{array}$ \\
& & $0.100^{* * *}$ & 0.021 & $-0.150^{* * *}$ \\
In restricted & 1,994 & $(0.019)$ & $(0.023)$ & $(0.017)$ \\
\hline Includes non-answers & Yes & Yes & No & Yes \\
\hline Observations & 3,001 & 3,001 & 2,231 & 3,001 \\
\hline \hline Note: & & & ${ }^{*} \mathrm{p}<0.1 ;{ }^{* *} \mathrm{p}<0.05 ;{ }^{* * *} \mathrm{p}<0.01$
\end{tabular}

\section{G.1.2 Non Weighted Results}

Despite the adoption of the method of quotas to constitute the main sample (which did not take highest degrees into account), higher educated people are largely over-represented in the non-weighted sample: only $24 \%$ do not have the Baccalauréat 43 in the sample as opposed to $55 \%$ in the general population. Hence, the weights bring the distribution of degrees much closer to the reality 44 However, had the results be computed without weights, they could have changed of one or two percents, but they would not have been significantly different, as is shown in Table 15 This is not surprising, as we have seen that approving a reform was not correlated with the highest degree of the respondent. Finally, only omitted or unobservable variables could have caused a sample bias, the main socio-demographic characteristics having been addressed.

Table 15: Effect of weighting on approval of a reform

\begin{tabular}{lccccc}
\hline \hline & \multicolumn{5}{c}{ Approval of a reform } \\
\cline { 2 - 6 } & Any reform & Average & Demogrant median & Median & Distortionary median \\
& $(1)$ & $(2)$ & $(3)$ & $(4)$ & $(5)$ \\
\hline Effect of weighting & -0.004 & 0.003 & 0.010 & -0.017 & -0.012 \\
& $(0.007)$ & $(0.015)$ & $(0.015)$ & $(0.015)$ & $(0.015)$ \\
Constant & $0.452^{* * *}$ & $0.418^{* * *}$ & $0.383^{* * *}$ & $0.539^{* * *}$ & $0.467^{* * *}$ \\
& $(0.011)$ & $(0.022)$ & $(0.022)$ & $(0.022)$ & $(0.023)$ \\
\hline Observations & 1,994 & 509 & 488 & 505 & 492 \\
\hline \hline
\end{tabular}

Note: $\quad{ }^{*} \mathrm{p}<0.1 ;{ }^{* *} \mathrm{p}<0.05 ;{ }^{* * *} \mathrm{p}<0.01$

\section{G.1.3 Quality of Responses}

Some variables enable to measure the quality of the responses, which can be affected voluntarily or not. Indeed, the time of response to several questions, including those on the approval of the average and demogrant reforms, have been recorded: they reveal the extent of voluntary effort to understand the questions 45 At the end of the surveys, the respondents were asked whether they had understood the questions with graphics: this shows the level of (involuntary) understanding 46 Both variables exhibit the same outcomes, as one can see in Table 16: the quality of a response is positively correlated with non-answering, but it is not significantly correlated with the rate of approval of a reform, after excluding PNR (People Not Responding). This absence of correlations achieves the validation of internal robustness: indeed, it demonstrates that the findings are not driven by a potential lack of seriousness of the responses or a low understanding of the questions.

\footnotetext{
43 The Baccalauréat is the examen concluding high-school. Source: insee.fr/fr/statistiques/1906701

44 The weighted share of respondents without Baccalauréat is thus $42 \%$. This figure is still a bit away from the reality, because weights have been trimmed in order to be in $[1 / 4 ; 4]$ : indeed, authorizing too large weights would have hampered the precisions of estimates.

45 The global response time and the number of clicks for different questions have also been recorded; they appear to be uncorrelated with our variables of interest.

46 The phrasing was the following: "Did you struggle understanding the questions with graphics?". $56 \%$ answered "No, it was fine (I got it eventually)" while the rest chose "Yes, sometimes I did not know how to answer".
} 
Table 16: Correlation between approval of a reform and quality of a response (OLS)

\begin{tabular}{|c|c|c|c|c|c|c|}
\hline & \multicolumn{4}{|c|}{ Approval of any reform } & \multicolumn{2}{|c|}{ Non-answer } \\
\hline & $(1)$ & $(2)$ & $(3)$ & $(4)$ & $(5)$ & $(6)$ \\
\hline log time response (at approval) & $\begin{array}{c}0.083^{* * *} \\
(0.022)\end{array}$ & $\begin{array}{c}0.027 \\
(0.027)\end{array}$ & & & $\begin{array}{c}-0.128^{* * *} \\
(0.017)\end{array}$ & \\
\hline Misunderstood graphic questions & & & $\begin{array}{c}-0.088 * * * \\
(0.022)\end{array}$ & $\begin{array}{c}0.008 \\
(0.026)\end{array}$ & & $\begin{array}{c}0.165^{* * *} \\
(0.018)\end{array}$ \\
\hline Constant & $\begin{array}{c}0.141^{* *} \\
(0.071)\end{array}$ & $\begin{array}{c}0.410^{* * *} \\
(0.088) \\
\end{array}$ & $\begin{array}{c}0.490^{* * *} \\
(0.015)\end{array}$ & $\begin{array}{c}0.566^{* * *} \\
(0.016)\end{array}$ & $\begin{array}{c}0.594^{* * *} \\
(0.056) \\
\end{array}$ & $\begin{array}{c}0.135^{* * *} \\
(0.012)\end{array}$ \\
\hline Includes non-answers & Yes & No & Yes & No & Yes & Yes \\
\hline Observations & 995 & 803 & 1,994 & 1,586 & 995 & 1,994 \\
\hline
\end{tabular}

\section{G.1.4 Comparison with an Earlier and Indirect Estimation}

In an earlier attempt whose result is shown in Appendix D Fabre (2016) derived the median favored redistribution for 43 countries from ISSP surveys, using responses of perceived and desired incomes of different professions (unskilled worker, doctor, chairman of a large corporation, etc.). The variability of answers concerning perceived current incomes provided the median desired income for a broad range of income, from which was inferred the median desired redistribution. As the questions used in this earlier estimate were not originally designed for this purpose, one could not interpret with certainty their implied desired redistribution in terms of a preference for a tax reform 47 Yet, the earlier results proved to be very similar to those revealed in this paper. The desired Gini coefficient implied by the earlier estimation of the median reform favored by French people is 0.30, almost in the range of 0.24-0.29 corresponding to Gini of proposed redistributions. Similarly, the earlier desired transfer from rich to poor of $11 \%$ of GNI falls in the range of the new estimations: 9-12\%, and so do other statistics reported in Appendix $\mathrm{A}$ income shares, the demogrant, the proportions of advantaged and disadvantaged by the reform... This convergence of results with two different methods both reinforces the credibility of the proposed redistributions as favored reforms and validates the estimations of desired redistributions by country of the earlier approach.

\footnotetext{
47 The desired redistribution estimated in this earlier work has to be understood in a broad sense, including for example a renegotiation of the wage scale. See Fabre $(\underline{2016})$ for a discussion on the hypotheses and the method.
} 